NOAA Technical Report NESS 78.

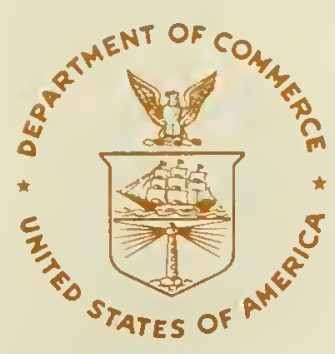

\title{
Geostationary \\ Operational Environmental \\ Satellite/Data Collection \\ System
}

Washington, D.C.

July 1979

QH

541.15

$m 64$

45

1979
U.S. DEPARTMENT OF COMMERCE

National Oceanic and Atmospheric Administration

National Environmental Satellite Service 
The Vational Environmental Satellite Service (NESS) is responsible for the establishment and operation of the environmental satelite systems of NOAA.

Publication of a report in NOAA Technlcal Report NESS series will not preclude Iater publication in an expanded or modifled form in sclentific journals. NESS series of NOAA Technical Reports 1 s a continuation of, and retains the consecutive numbering sequence of, the former series, ESSA Technical Report National Environmental Satellite Center (NESC), and of the earlier serfes, Weather Bureau Meteorological Satellite Laboratory (MSL) Report. Reports 1 through 39 are listed in publication NESC 56 of this ser1es.

Reports in the series are available from the National Technical Information Service (NTIS), U.S. Department of Commerce, Sills Bldg., 5285 Port Royal Road, Springfield, VA 22161, in paper copy or microfiche form. Order by accession number, when given, in parentheses. Beginning with 64, printed copies of the reports, if avallable, can be ordered through the Superintendent of Documents, U.S. Govermment Printing Office, Washington, DC 20402. Prices given on request from the Superintendent of Documents or NTIS.

\section{ESSA Technical Reports}

NESC 43 Atlas of World Maps of Long-Wave Radiation and Albedo--for Seasons and Months Based on Measurements From TIROS IV and TIROS VII. J. S. Winston and V. Ray Taylor, September 1967,32 pp. $(\mathrm{PB}-176-569)$

NESC 44 Processing and Display Experiments Using Digitized ATS-1 Spin Scan Camera Data. M. B. Whitney, R. C. Doolfttle, and B. Goddard, April 1968, 60 Pp. (PB-178-424)

NESC 45 The Nature of Intermedtate-Scale Cloud Spirals. Linwood F. Whitney, Jr., and Leroy D. Herman, May 1968, 69 pp. plus appendixes A and B. (AD-673-681)

NESC 46 Monthly and Seasonal Mean Global Charts of Brightness From ESSA 3 and ESSA 5 Dig1tized P1Ctures, February 1967-February 1968. V. Ray Taylor and Jay S. Winston, Noveraber 1968,9 pp. plus 17 charts. (PB-180-717)

NESC 47 A Polynomial Representation of Carbon Dioxide and Water Vapor Transmission. William L. Smith, February 1969 (reprinted April 1971), 20 pp. (PB-183-296)

NESC 48 Statistical Estimation of the Atmosphere's Geopotential Helght Distribution From Satellite Radiation Measurements. William L. Smith, February 1969, 29 pp. (PB-183-297)

NESC 49 Synoptic/Dynamic Diagnosis of a Developing Low-Level Cyclone and Its Satelife-Viewed Cloud Patterns. Harold J. Brodrlck and E. Paul McClain, May 1969, 26 pp. (PB-184-612)

NESC 50 Estimating Maximum Wind Speed of Tropical Storms From High Resolution Infrared Data. L. Hubert, A. Tímchalk, and S. Fritz, May 1969, 33 pp. (PB-184-6I1)

NESC 51 Application of Meteorological Satellite Data in Analysis and Forecasting. Ralph K. Anderson, Jerome P. Ashman, Fred Bittner, Golden R. Farr, Edward W. Ferguson, Vincent J. Oliver, Arthur H. Smith, James F. W. Purdom, and Rance W. Skidmore, March 1974 (reprint and revision of NESC 51, September 1969, and inclusion of Supplement, November 1971, and Supplement 2, March 1973), pp. $1--6 \mathrm{C}-18$ plus references.

NESC 52 Data Reduction Processes for Spinning Flat-Plate Satellite-Borne Radiometers. Torrence H. MacDonald, July 1970,37 pp. (COM-71-00132)

NESC 53 Archiving and Climatological Applications of Meteorological Satellite Data. John A. Leese, Arthur L. Booth, and Frederick A. Godshall, July 1970, pp. 1-1--5-8 plus references and appendixes A through D. (COM-71-00076)

NESC 54 Estimating Cloud Amount and Helght From Satellite Infrared Radiation Data. P. Krishna Rao, July 1970, Il pp. (PB-194-685)

NESC 56 Time-Longitude Sections of Tropical Cloudiness (December 1966-November 1967). J. M. Wallace, July $1970,37 \mathrm{pp}$. (COM-71-00131)

(Continued on inside back cover) 


\section{NOAA Technical Report NESS 78}

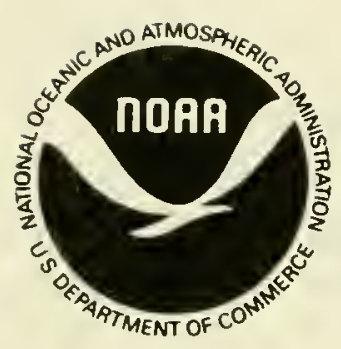

\section{Geostationary Operational Environmental Satellite/Data Collection System}

Office of System Engineering

Washington, D.C.

July 1979

\section{U.S. DEPARTMENT OF COMMERCE Juanita M. Kreps, Secretary}

National Oceanic and Atmospheric Administration

Richard A. Frank, Administrator

National Environmental Satellite Service

David S. Johnson, Director 
DISCLAIMER. "Mention of a commercial company or product does not constitute an endorsement by NOAA National Environmental Satellite Service. Use for publicity or advertising purposes of information from this publication concerning proprietary products or the tests of such products is not authorized."
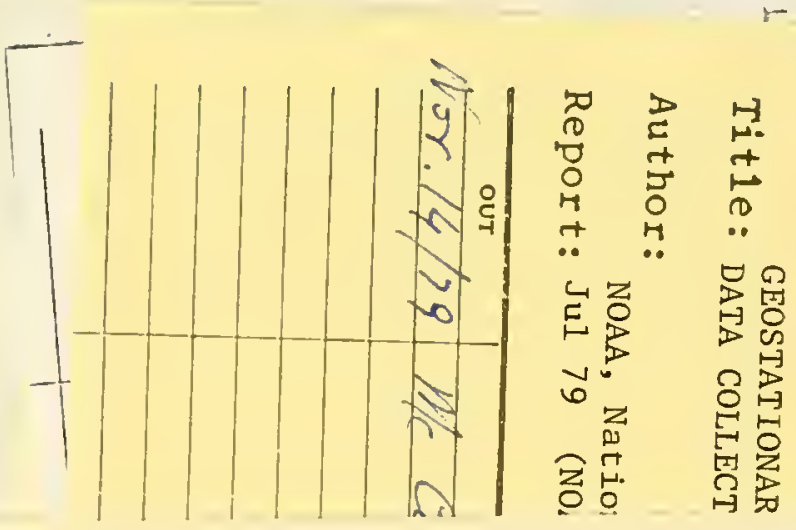


\section{CONTENTS}

Glossary

vi

Abstract

viii

1

Introduction

1. 1

GOES system description

1.1 .1

What is GOES?

1.1 .2

How is the GOES system implemented?

1.1 .3

What does GOES do?

1.1.3.1 Visible and Infrared Spin-Scan

1.1.3.2 Retransmission of VISSR and WEFAX data 1

1.1.3.3 Space Environment Monitoring (SEM) 2

1.1.3.4 Command and telemetry 2

1.1.3.5 Data collection 2

1.1.4 Is there a standby satelite?

1.1.5 Will service interruptions occur? 2

1.2 Description of the Data Collection Subsystem 2

1.2.1 How can an organization become a GOES/DCS 2

1.2.2 What does it cost? 3

1.2.3 What geographical coverage is provided by 3

1.2.4 What is the DCS message capacity?

1.2.5 What type of user sensor platform can be used? 3

1.2.6 How are transmitter frequency assignments 6

1.2.7 How do the sensor data reach the user? 6

1.2.8 How is the DCS operation controlled?

1.2.9 What data error probability can the DCS 8

1.2.10 Can a user achieve direct data readout from 8 the GOES satellite?

2 A CLOSER LOOK AT THE DCS

2.1 DCS general operation 10

2.2 Sensor/platform interface 10

$\begin{array}{lll}2.2 .1 & \text { Sensor data format } & 10\end{array}$ 


\section{CONTENTS (Con.)}

2.2.2 Sensor platform transmitter response format 14

2.2.3 Command/interrogate signal format 14

$\begin{array}{lll}2.2 .4 & \text { Platform radio set characteristics } & 17\end{array}$

$\begin{array}{lll}2.2 .5 & \text { Environmental considerations } & 17\end{array}$

2.3 Spacecraft function in the DCS 17

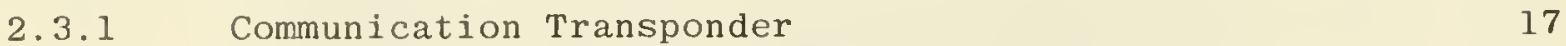

2.3.2 Conditions affecting access and performance 18

$\begin{array}{lll}2.4 & \text { Command and data acquisition } & 18\end{array}$

2.4.1 Response data and command/interrogate signals 18

2.4.2 Time data and command/interrogate signal format 19

2.4.3 Response data demodulation and transmission to 19

2.5 Data Recovery-Central Distribution Facility 20

2.5.1 Recovered data characteristics 20

2.5.2 Error checks and abnormal responses 20

2.5 .3 User access to recovered data 21

2.5.3.1 User dissemination circuits 21

2.5.3.2 Dedicated circuit 21

2.5.3.3 1200-baud DDD circuit 24

$\begin{array}{lll}2.5 .3 .4 & 110 \text {-baud DDD circuit } & 27\end{array}$

REFERENCES

Appendix A - Users Request Questionnaire

Appendix B - Memorandum of Agreement Between NOAA and the User

Appendix C - DCPRS Certification Standards (Interrogated \& Self-Timed)

Appendix D - Some Considerations in the Design and Installation of a Receiving System To Receive DCS Data Directly From the SMS/ GOES Family of Satellites

Appendix E - Certification Specifications for International DCPRS 


\section{LIST OF FIGURES}

1.--Geometry of the DCS coverage 4

2.--SMS/GOES coverage $\quad 5$

3.--GOES data collection system 9

$\begin{array}{ll}\text { 4.--ASCII character assignments } & 11\end{array}$

5.--Pseudo-ASCII binary data format 12

6.--Modulation definition 13

7.--Platform transmitter response timing 13

8.--Interrogation message and time code formats 15

\section{LIST OF TABLES}

1 TI 742 command characters

24 


\section{GLOSSARY}

ASCI I

BER

BPS, bps

CDA

CPS

CRC

dB

$\mathrm{dBm}$

DCPRS

DCS

DDD

CDF

e.g. :

EIRP

$\mathrm{E} / \mathrm{N}$ 。

GOES

$\mathrm{Hz}$

IBM

ID

LRC

LSB

$\max$
American Standard Code for Information Interchange Bit Error Rate

Bits per second

Command and Data Acquisition

Characters per second

Cyclic Redundancy Check

Decibels

Decibels referred to 1 milliwatt

Data Collection Platform Radio Set

Data Collection System

Direct Distance Dial

Central Distribution Facility

for example

Effective Isotropic Radiated Power

Bit Energy to noise spectral power density ratio Geostationary Operational Environmental Satellite Hertz

International Business Machines Corporation Identification

Longitudinal Redundancy Check

Least Significant Bit

Maximum 
GLOSSARY (Con.)

\begin{tabular}{ll} 
min & Minimum \\
MLS & Maximal Linear Sequence \\
NASA & National Aeronatics and Space Administration \\
NBS & National Bureau of Standards \\
NESS & National Environmental Satellite Service \\
NOAA & National Oceanic and Atmospheric Administration \\
op. cit. & In the work cited \\
PSK & Phase shift keyed, -ing \\
P & Probability that the transmission path loss will \\
RCP & be less than the value used \\
S/C & Right-hand Circularly Polarized \\
S & Spacecraft \\
SEM & Seconds \\
SFSS & Space Environment Monitoring \\
SMS & Satellite Field Service Stations \\
Sync & Synchronous Meteorological Satellite \\
UHF & Synchronization \\
UTC & Ultra High Frequency \\
vISSR & Coordinated Universal Time \\
WEFAX & Visible and Infrared Spin-Scan Radiometer \\
& Weather Facsimile \\
\hline
\end{tabular}


GEOSTATIONARY OPERATIONAL ENVIRONMENTAL SATELLITE/ DATA COLLECTION SYSTEM

ABSTRACT. The Data Collection System portion of the NOAA Geostationary Operational Environmental Satellite program has the potential and capacity for many and varied uses. The purpose of this report is to describe to potential users the carrier system and its data processing capabilities. User qualifications and requirements for participation in the Data Collection System are also defined. 
SECTION 1

INTRODUCTION

\subsection{GOES System Description}

\subsubsection{What Is GOES?}

The United States of America Geostationary Operational Environmental Satellite (GOES) service is an integrated system of Earth and space environmental sensors which provide nearly continuous observational information to ground-based user stations. The service is operated and controlled by the National Oceanic and Atmospheric Administration (NOAA) of the U.S. Department of Commerce, and was developed at the National Environmental Satellite Service (NESS) in conjunction with the Synchronous Meteorological Satellite (SMS) program of the U.S. National Aeronautics and Space Administration (NASA).

\subsubsection{How Is the GOES System Implemented?}

The GOES service currently operates two satellites located in Earthsynchronous orbits approximately 35,500 kilometers above the Equator at longitude $75^{\circ} \mathrm{W}$ and longitude $135^{\circ} \mathrm{W}$. Both satellites are controlled from the NOAA Command and Data Acquisition (CDA) Station at Wallops Station, Virginia.

\subsubsection{What Does GOES Do?}

The GOES service performs five missions. Each of the missions is carried out by a dedicated subsystem, as described below.

\subsubsection{Visible and Infrared Spin-Scan Radiometer (VISSR)}

Each satellite has a visible/infrared radiometer that provides nearly continuous imaging of the viewed portion of the Earth's surface and cloud cover. The visible images are produced during daytime, whereas the infrared images provide day and night coverage.

\subsubsection{Retransmission of VISSR and WEFAX Data}

The CDA is uniquely equipped to receive the high-speed VISSR data from the spacecraft. These data are reformatted at the CDA and retransmitted through the spacecraft transponder to Satellite Field Service Stations (SFSS) within view of the spacecraft. SFSS activities located in San Francisco, California; Kansas City, Missouri; Suitland, Maryland; Miami, Florida; Honolulu, Hawaii; and Anchorage, Alaska, currently receive and process the retransmitted VISSR data for distribution to weather forecast stations throughout the United States.

In a similar fashion, Weather Facsimile (WEFAX) pictures are transmitted through the spacecraft transponder to such users as ships at sea. aircraft, and weather forecast stations located within view of the spacecraft. 


\subsubsection{Space Environment Monitoring (SEM)}

SEM equipment onboard the spacecraft measures the energy and trajectory of incident particles. These data are transmitted to the Space Disturbance Forecast Center at Boulder, Colorado, for distribution and analysis.

\subsubsection{Command and Telemetry}

The "housekeeping" functions necessary to maintenance of correct attitude and position, and monitoring spacecraft status, etc., are provided by the Command and Telemetry subsystem under control of the CDA Station.

\subsubsection{Data Collection}

The Data Collection capability enables atmospheric and Earth-based sensors within view of the spacecraft to transmit synoptic or interrogated data to the CDA through the spacecraft transponder. These data are relayed to the Central Distribution Facility (CDF) at Suitland, Maryland, for dissemination to users.

\subsubsection{Is There a Standby Satellite?}

To serve as a backup in event of failure of either operational satellite there is a third geostationary satellite in orbit at longitude $105^{\circ} \mathrm{W}$ (located midway between the other two). The backup satellite can readily be moved to either the east or west satellite position should such a need arise.

\subsubsection{Will Service Interruptions Occur?}

There may be interruptions during the periods of solar eclipses. The GOES satellites undergo spring and autumn eclipses during a 46-day interval at the vernal and autumnal equinoxes. The eclipses vary from approximately 10 minutes at the beginning and end of eclipse periods to a maximum of approximately 72 minutes at the equinox. The eclipses begin 23 days prior to equinox and end 23 days after equinox; i.e., March 1 to April 15 and September 1 to October 15. The outages occur during local midnight for the satellites' mean meridian. There will also be shutdowns for periodic maintenance at the Wallops CDA station. These scheduled outages will be reduced in the future as redundancy is added to the Wallops Station facility.

\subsection{Description of the Data Collection Subsystem}

In consonance with the primary purpose of this brochure, the following paragraphs discuss in some detail those aspects of the Data Collection System that will be of particular interest to users.

\subsubsection{How Can an Organization Become a GOES/DCS User?}

An organization having a requirement for data collection, or which plans to collect data using the GOES DCS capability, must formally request permission to participate. Requests are processed by: National Oceanic and Atmospheric Administration, National Environmental Satellite Service, Washington, D.C. 20233. 
The prospective user must describe the proposed use of the DCS for examination by the NESS DCS Review Committee, which recommends appropriate action to be taken by the Director of NESS on the request. A questionnaire (see Appendix A) is provided to facilitate presentation of information needed to properly consider the user's request.

Upon approval of the user's request for participation in the DCS, a Memorandum of Agreement will be prepared to detail the rights and responsibilities of both NESS and the participating user. This agreement is attached as Appendix B.

\subsubsection{What Does It Cost?}

Collection of data from user sensor platforms and processing the data for dissemination using the GOES DCS facilities is without charge to the user. The user will be responsible for his own costs of sensor platforms, such as procurement, maintenance, and installation, and such tests as are required to establish conformity to the DCS performance specifications. The user will also be responsible for the costs of communications lines, modem equipment, and data terminals necessary to the dissemination capability of the GOES/DCS. Unless an exception is justified, data collected for individual users will be made available by NESS to other users or interested parties upon request.

1.2.3 What Geographical Coverage Is Provided by the DCS?

The DCS was based on the practicality of an Earth-sited transmitter operating with a suitable antenna to provide an Effective Isotropic Radiated Power (EIRP) of $50 \mathrm{dBm}$ ( $\max$. ) at a minimum antenna elevation angle of less than $5^{\circ}$. The minimum antenna elevation angle defines the portions of the Earth's surface having geocentric angles up to approximately $77^{\circ}$, measured from the subsatelite point. Figure 1 described the geometry of the DCS. Figure 2 presents the actual Earth surface coverage for the DCS of both GOES satellites.

\subsubsection{What Is the DCS Message Capacity?}

Access to the spacecraft transponder is shared among all platform site transmitters within its field of view. (See Figure 2.) The DCs has the capacity for handling at least 10,000 transmissions (30-s average message duration) from platform sites via the spacecraft transponder in each 1 -hour period. Frequency division multiple access with timeshared channel occupancy is the technique used to meet the data traffic requirements. 200 channels are available for domestic user assignment with an additional 33 channels provided for cooperative working with international users. The channel spacing accommodates the 100-bits-persecond DCS message data rates.

1.2.5 What Type of User Sensor Platform Can Be Used?

The simplest user platform configuration requires:

(1) An LHF transmitter and antenna combination capable of producing $+50 \mathrm{dBm}$ EIRP. 


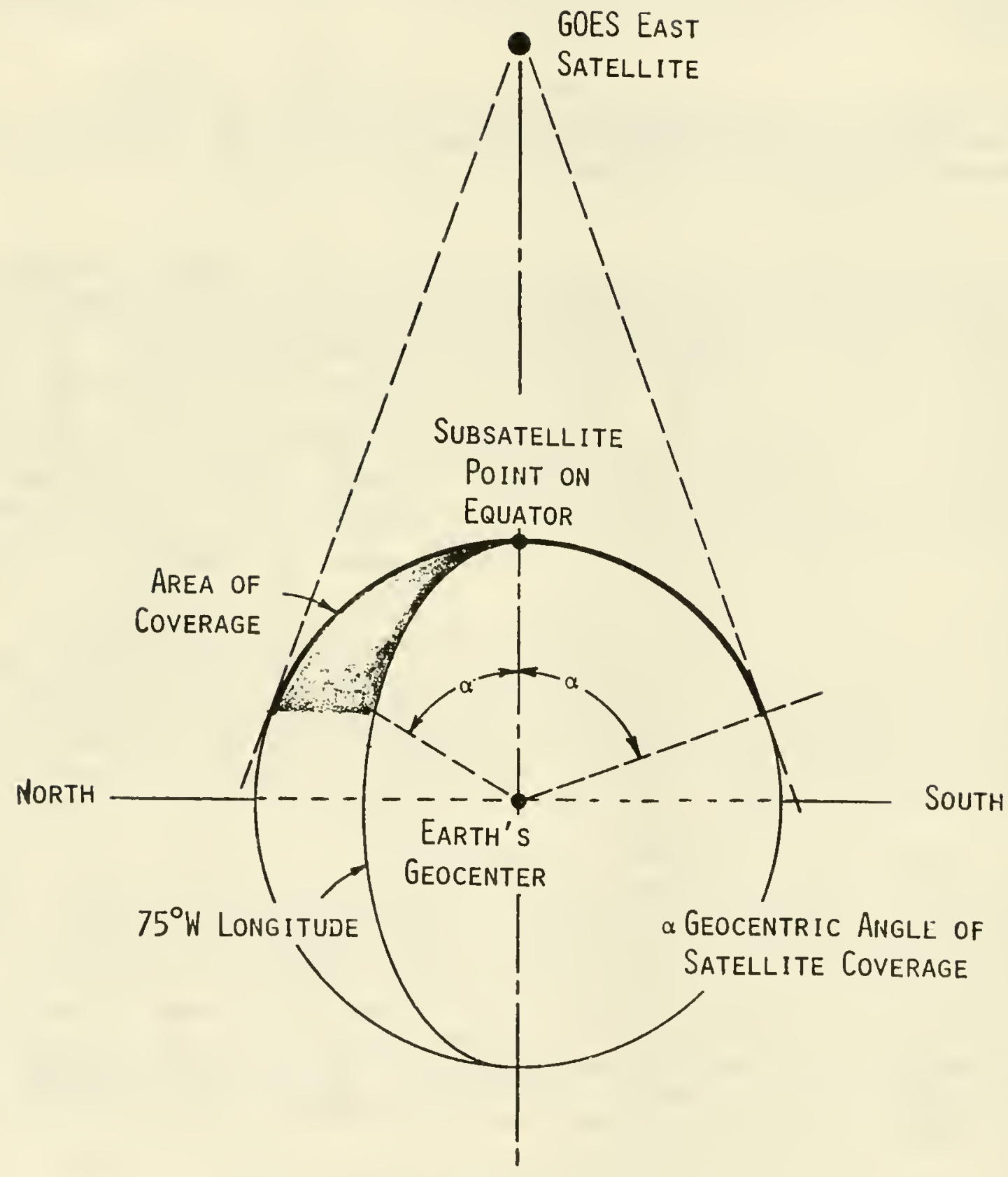

FIGURE 1

GEOMETRY OF THE DCS COVERAGE 


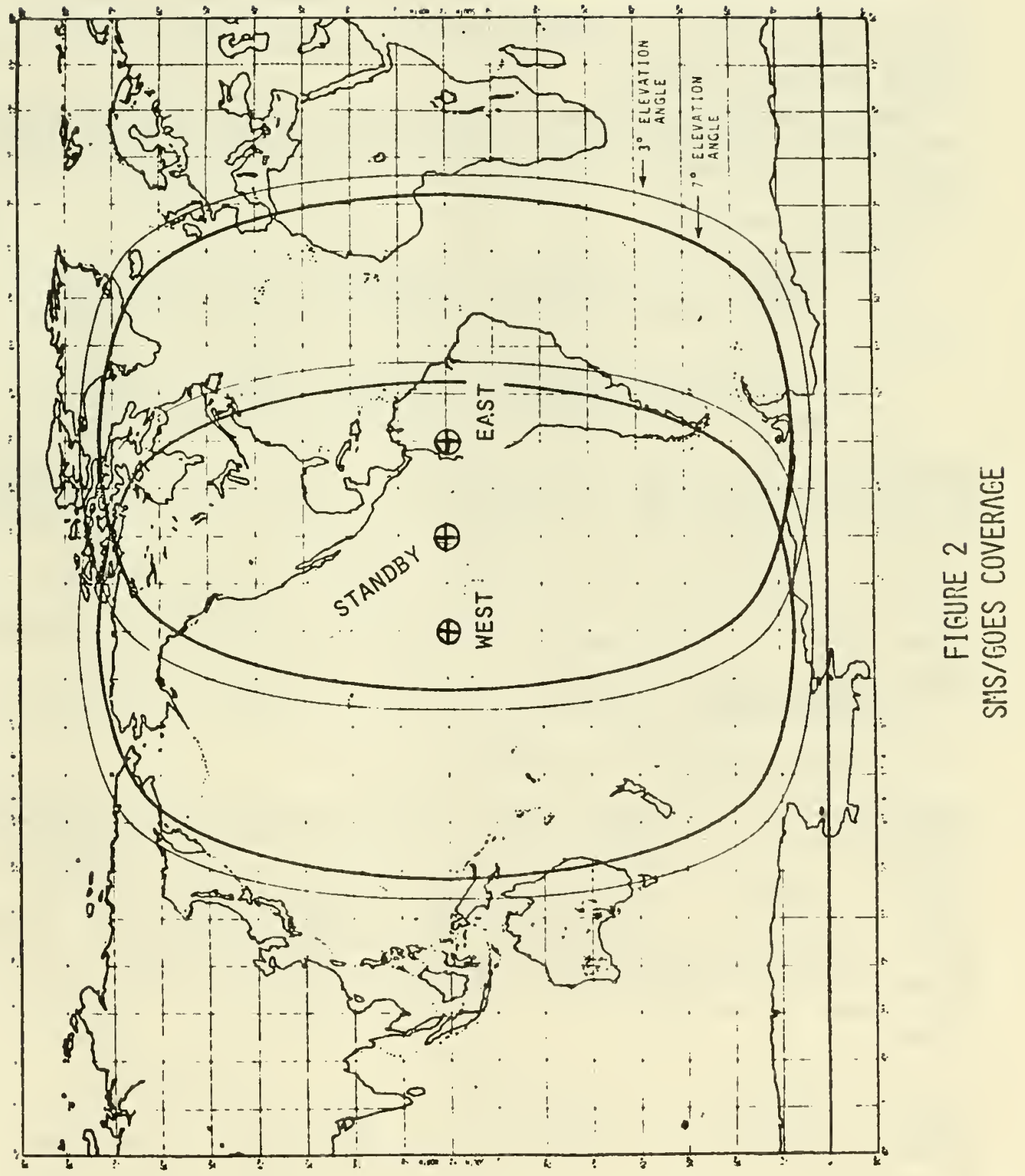


(2) A sensor data interface to provide ASCII data coding and formatting.

(3) A timer, or sensor threshold logic, to initiate transmission on a regular timed basis, or on the detection of conditions exceeding predetermined levels.

The addition of an UHF receiver capable of receiving and decoding the command/interrogate signal provides the capability of remotely commanding sensor platform responses.

To qualify for participation in the GOES DCS, the data being collected must be observations and measurements of physical, chemical, or biological characteristics of the Earth or its surrounding space. A wide variety of sensor platforms can work with the Data Collection System, for example:

(I) fixed location sensors; temperature, wind, and rainfall gages on land and sea; river level and tiae gages; seismic detectors; experimental environmental monitors.

(2) mobile sensors; balloon and aircraft-borne monitors; free-floating ocean environmental sensors; shipboard weather and oceanographic reporting stations.

Any platform that has been demonstrated to meet the DCS performance specifications (Appendix C) may be used. A current list of approved platforms may be obtained from NESS.

\subsubsection{How Are Transmitter Frequency Assignments Obtained?}

When an organization is accepted as a DCS user, the sensor platform transmitter channel frequency assignments are provided by NESS. The user, however, is responsible for obtaining authority from the appropriate national agencies to operate each platform transmitter at its deployed location.

\subsubsection{How Do the Sensor Data Reach the User?}

Transmission of data from the user sensor platform may be initiated in several ways. The platform site transmitter may be commanded to transmit the sensor data, using the interrogation capability of the DCS. The transmitter may be activated at regular time intervals under the control of an internal timer. Sensor threshold or abnormal conditions may be used to trigger transmission of emergency information or data requiring immediate attention (such as seismic activity). Generally, transmissions initiated by different means (interrogated, self-timed, or emergency) will not share occupancy of a common response channel.

Each sensor platform site transmitter is assigned at least one 31-bit address identifier. The address identifiers are part of the required format for transmission of sensor data, and are used by the data processing subsystem to route the data to the user. Once a message is received by the DCS, it is entered in the system events $\log$ and 
stored in the appropriate user's area of the data output buffer to await dissemination. The preferred method of dissemination is in real time over a dedicated communication channel assigned to the user. Alternative arrangements, such as dissemination over dialup circuits, may also be used.

\subsubsection{How Is the DCS Operation Controlled?}

DCS operation is controlled by the Data Processing Subsystem computer which handles the routine functions of message scheduling, status reporting, data reception, buffering, and dissemination. Manual operator intervention is provided for startup procedures.

Control of the DCS is exercised by comparison of real-time system activity to the system schedule stored in the computer. Messages are periodically sent by the computer to the CDA subsystem which include platform address identifiers scheduled for activity, channel occupation, and time of report, and whether the reporting platform is self-timed or requires interrogation. The CDA equipment receives the platform sensor data transmitted through the satellite transponder, performs character error checks, and temporarily stores the data. The received messages are checked at the CDA for expected address identifiers and transmitted to the World Weather Building Central Distribution Facility (CDF), along with all pertinent error information. If a scheduled message was not received at the expected time, the CDF computer notifies the user. The occurrence of an unexpected (unscheduled) platform message is analyzed by the computer to determine whether it was due to an equipment malfunction, platform site transmitter test, or emergency condition, with appropriate action automatically being taken and abnormal status indication provided to the user.

Received sensor platform messages and abnormal response messages are formatted into bulletins in the CDF data buffer. Dissemination of these bulletins to users will be attempted in real time, as the data replies are received, over the dedicated circuit assigned to the user. Reformatting of platform response data is not performed; these data appear unmodified in the bulletins disseminated to the users. Users must consider the effect of their platform sensor data format on their data terminal, e.g.:

(1) Requirements for carriage return, line feed, and characters needed for proper display.

(2) Compatibility of the terminal character set with the transmitted characters.

(3) Use of characters or character sequences for special purposes. 


\subsubsection{What Data Error Probability Can the DCS User Expect?}

Under reasonable conditions, the user can expect to obtain a bit error probability of $10^{-5}$ or better, using data received at the CDA and provided to the user at the Central Distribution Facility (CDF) at Camp Springs, Maryland.

Various factors affect the data quality. Some of these are determined by the GOES system design, and some are related to instantaneous spacecraft usage and propagation conditions. Appendix $D$ treats the considerations involved in reception at Earth terminals other than the CDA.

The spacecraft down-link power at $\mathrm{S}$-band is shared between the CDF response and occasional TIROS-N data relay transmissions. As the number of DCP's increases, somewhat less power is available to each simultaneously active channel. Furthermore, simultaneous operation of the VISSR subsystem reduces the total power available to the DCP/ TIROS-N down-link transmission by 4 to $5 \mathrm{~dB}$. Sufficient power margin is provided in the system design to accommodate full anticipated loading under the above worst-case power sharing conditions when utilizing the CDA or an equivalent performance ground terminal.

Other factors that can affect data qualityl are the DCP's geographic location with respect to the spacecraft, as losses are slightly higher at the "Farth's edge"; multipath propagation, in which DCP signals reflected from the ground, ocean, etc., interfere with direct signals; and ionospheric scintillation, which may occasionally produce greater than normal path attenuation. Maintenance of the DCP, adjustment of the DCP antenna positioning, and provision of an unobstructed path to the GOES are essential to minimum-error performance.

\subsubsection{Can a User Achieve Direct Data Readout From the GOES} Satellite?

Any user, with discretion, may implement a data collection ground receiving terminal and thereby achieve direct readout of the $S$-band reply data from the GOES satellite. This secondary data collection terminal enables a user to be independent of the primary CDA data collection receive terminal. However, the user will be required to adhere to the channel assignments and schedules coordinated for the GOES system by NESS. The design constraints and characteristics required of such a secondary user-owned data collection terminal are presented in Appendix D.

1 At the CDA, the present demodulators are sensitive to data patterns, and some characters of the ASCII set cause difficulty. This problem is being remedied. 


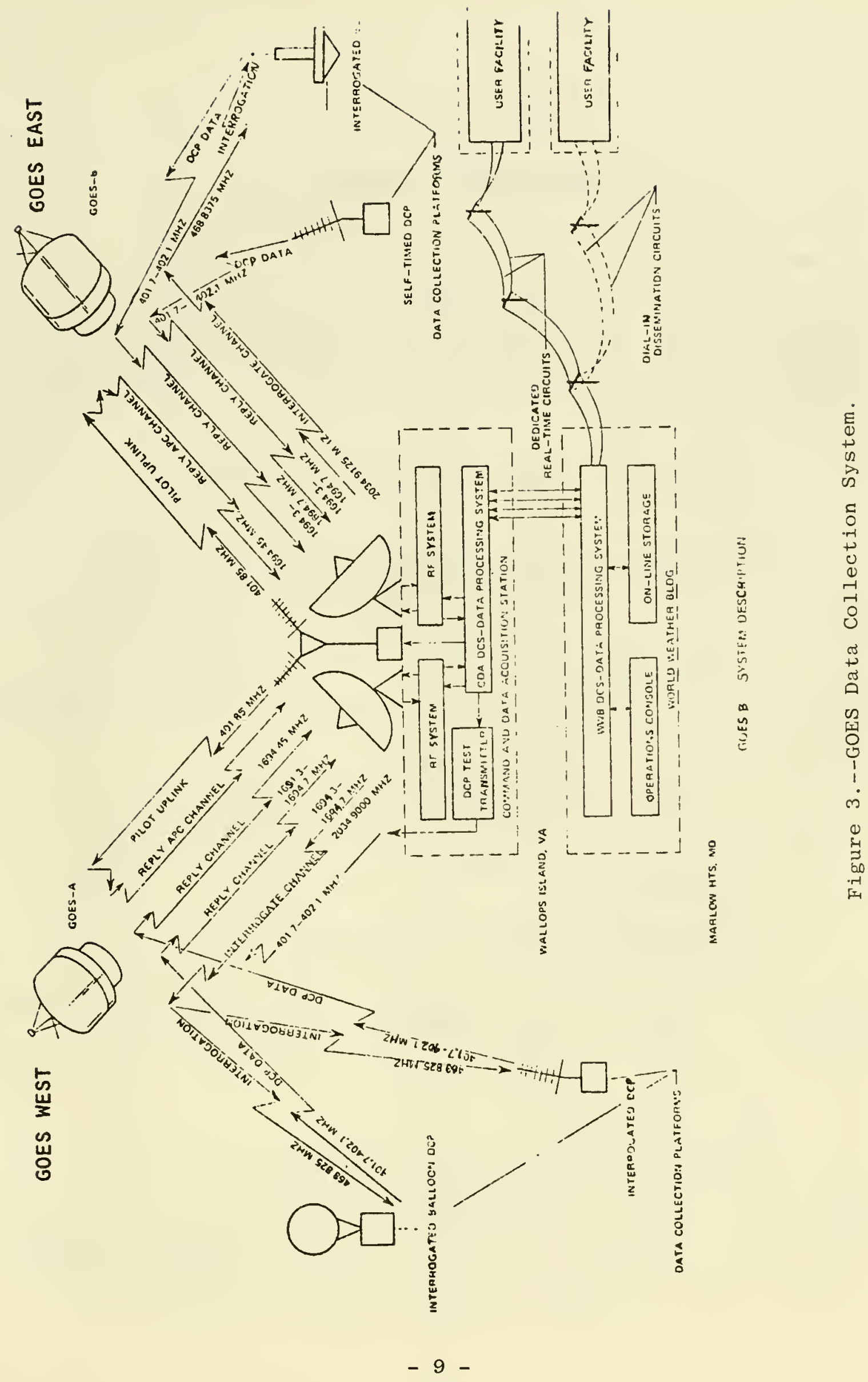




\section{SECTION 2}

A CLOSER LOOK AT THE DCS

\subsection{DCS General Operation}

The GOES Data Collection System (DCS) is a communication system designed to be used by many organizations having the need to relay environmental data from remote sensors to the user's processing center on a timely basis. The system is designed to accommodate 10,000 individual sensor platform transmissions per hour operating in three possible modes:

(1) Interrogated; the sensor platform transmits its data in response to an interrogation signal from the CDF.

(2) Self timed; the sensor platform transmits its data at fixed (synoptic) intervals controlled by a timer located within the sensor platform.

(3) Emergency; the sensor platform transmits its data after a predetermined sensor threshold (trigger) level has been exceeded.

Figure 3 presents a pictorial diagram of the Data Collection System showing its major functional subsystems:

(1) Deployed sensor platforms; discussed in Section 2.2.

(2) East and West spacecraft; discussed in Section 2.3.

(3) Command and Data Acquisition Station (CDA); discussed in Section 2.4 .

(4) CDF and user dissemination circuits; discussed in Section 2.5.

The radio frequency plan for the DCS is shown in Figure 3 . The exact frequency or frequency range is associated with each specific function.

\subsection{Sensor/Platform Interface}

\subsubsection{Sensor Data Format}

The CDF computer is programed to make only those modifications to the sensor data necessary to disseminate the data to the user. No capability is provided for analysis or interpretation of sensor data or for code conversion or error correction. Sensor data are expected to be binary-coded ASCI I characters (conforming to the 128-character code set shown in Figure 4) transmitted serially (least-significant bit first), with odd parity determining the eighth bit for each 


\begin{tabular}{|c|c|c|c|c|c|c|c|c|}
\hline$b_{4} b_{3} a_{2} b_{1}$ & $b_{1}, b_{1 ;} b_{1}=0$ & 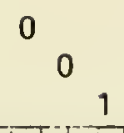 & 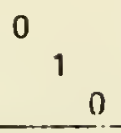 & 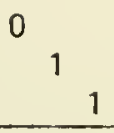 & $\begin{array}{ll}1 & \\
& 0 \\
& 0 \\
\end{array}$ & $\begin{array}{lll}1 & & \\
& 0 & \\
& & \\
& & 1 \\
\end{array}$ & $\begin{array}{ll}1 & \\
& 1 \\
& \\
& 0 \\
\end{array}$ & 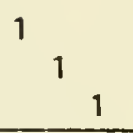 \\
\hline 0000 & NUL & IOLE & SPACE & 0 & (i) & P' & 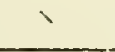 & 1) \\
\hline $\begin{array}{lllll}0 & 0 & 0 & 1\end{array}$ & SOII & DC1 & $!$ & 1 & $A$ & 0 & i) & 9 \\
\hline $\begin{array}{llll}0 & 0 & 1 & 0 \\
\end{array}$ & STX & $\mathrm{DC2}$ & $"$ & 2 & $B$ & II & b & 1 \\
\hline $\begin{array}{llll}0 & 0 & 1 & 1\end{array}$ & ETX & $\mathrm{DC} 3$ & $1 t$ & 3 & C & $S$ & c & $s$ \\
\hline $\begin{array}{llll}0 & 1 & 0 & 0 \\
\end{array}$ & EOT: & UC1 & 5 & 4 & D & $T$ & i & $t$ \\
\hline $\begin{array}{llll}0 & 1 & 0 & 1\end{array}$ & ENO & INAK & 㷛 & 5 & $E$ & $U$ & $\because$ & 11 \\
\hline 0110 & ACK & SYN & 8 & G & $\mathrm{F}$ & V & 1 & v \\
\hline $\begin{array}{llll}0 & 1 & 1 & 1 \\
\end{array}$ & $B E L$ & ETB & 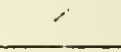 & 7 & (i) & $W$ & y] & $w$ \\
\hline 1000 & USU & $|C A N|$ & 1 & 8 & 11 & $x$ & 11 & $x$ \\
\hline $\begin{array}{llll}1 & 0 & 0 & 1\end{array}$ & $H$ & EM & 1 & 9 & 1 & $Y$ & i & $y$ \\
\hline 10010 & L $L F$ & Isuc & 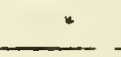 & $:$ & $d$ & $z$ & i & $z$ \\
\hline $\begin{array}{llll}1 & 0 & 1 & 1 \\
\end{array}$ & VT & ESC & + & : & K & l & k & 1 \\
\hline 1100 & FF & $F S$ & ' & $<$ & $\mathrm{L}$ & 1 & 1 & ! \\
\hline 1101 & dilcislinil & $\mathrm{GSS}^{1}$ & . & $=$ & $M$ & ] & 111 & \} \\
\hline 1110 & SO & Iis & . & $y$ & $N$ & $\wedge$ & 11 & 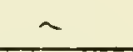 \\
\hline $\begin{array}{llll}1 & 1 & 1 & 1\end{array}$ & $\mathrm{SI}_{\mathrm{L}}$ & US: & 1 & $?$ & 0 & - & 0 & DELI \\
\hline
\end{tabular}

PizINTABLE character

PIINTER CONTHOL CHAKMCTEM

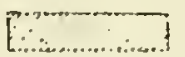

AUXII.IARY DEVICE CONTROL CHARACTER

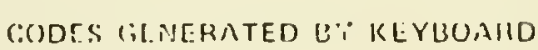
BUT FNO ACTION TAKLN

USASCII CONTROL CHARACTERS

(From USA Srandaris Inslilua Publicillon X3.1--1968)

\begin{tabular}{|c|c|c|c|}
\hline ACK & in:knowledlye & ETX & "nd of 1,21 \\
\hline$B \xi_{.} \mathrm{L}$ & $13: 11$ & 1.1 & Iorm lied \\
\hline BS & back bare: & r:s & lile srpillator \\
\hline rin & c.ll r:l & is & yroup sessister \\
\hline CH & cirriage ictull! & HIT & herieontal t.mbulation \\
\hline $\mathrm{DCl}=X \cdot \mathrm{ON}$ & rlevice contiol 1 & I. 5 & line: Irerd \\
\hline$D C 2=T A P E$ & elrvice conters 2 & NAK & neṇtive acknov:lexlyn. \\
\hline UCS $=X . O F F$ & Irevice continal 3 & NUL & muli \\
\hline DCA = TAPE & device contral a (stom) & ris & record separaters \\
\hline -DEL = ГUUB OUT & dיוlis & SI & sluft in \\
\hline DLE & d.1t.1 link rescialue & SO & shilt ont \\
\hline EM & rmol of mexlium & $\mathrm{SOH}$ & stive of lorrotiny \\
\hline EN(2) $=$ WIIIIs & "momi:y & six & 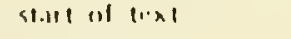 \\
\hline $10 \mathrm{~T}$ & 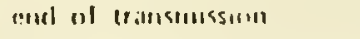 & silt & 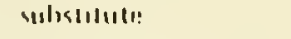 \\
\hline ESC & escipin & SYN & symclirmous ielle \\
\hline ETB & 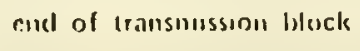 & us & Innit sepwatos \\
\hline & & $v r$ & vertical l.butation \\
\hline
\end{tabular}

- ol strictly a control clsuracen!

Figure 4.--ASCII Character Assignments. 


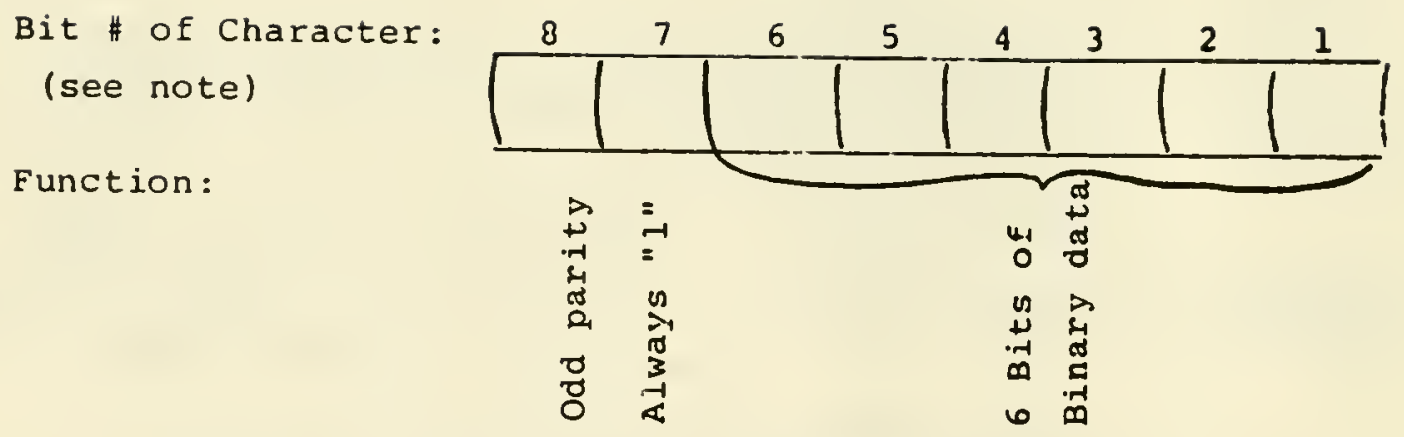

Figure 5.--Pseudo-ASCCII binary data format NOTE: Bit \# is order of transmission -- \#1 is first 


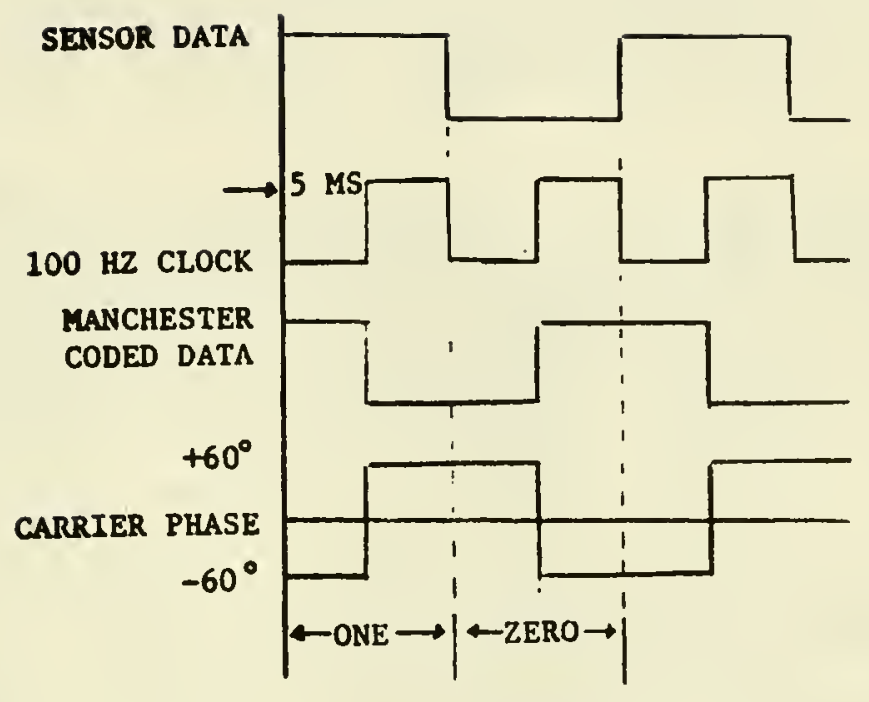

Figure 6.--Modulation Definition.

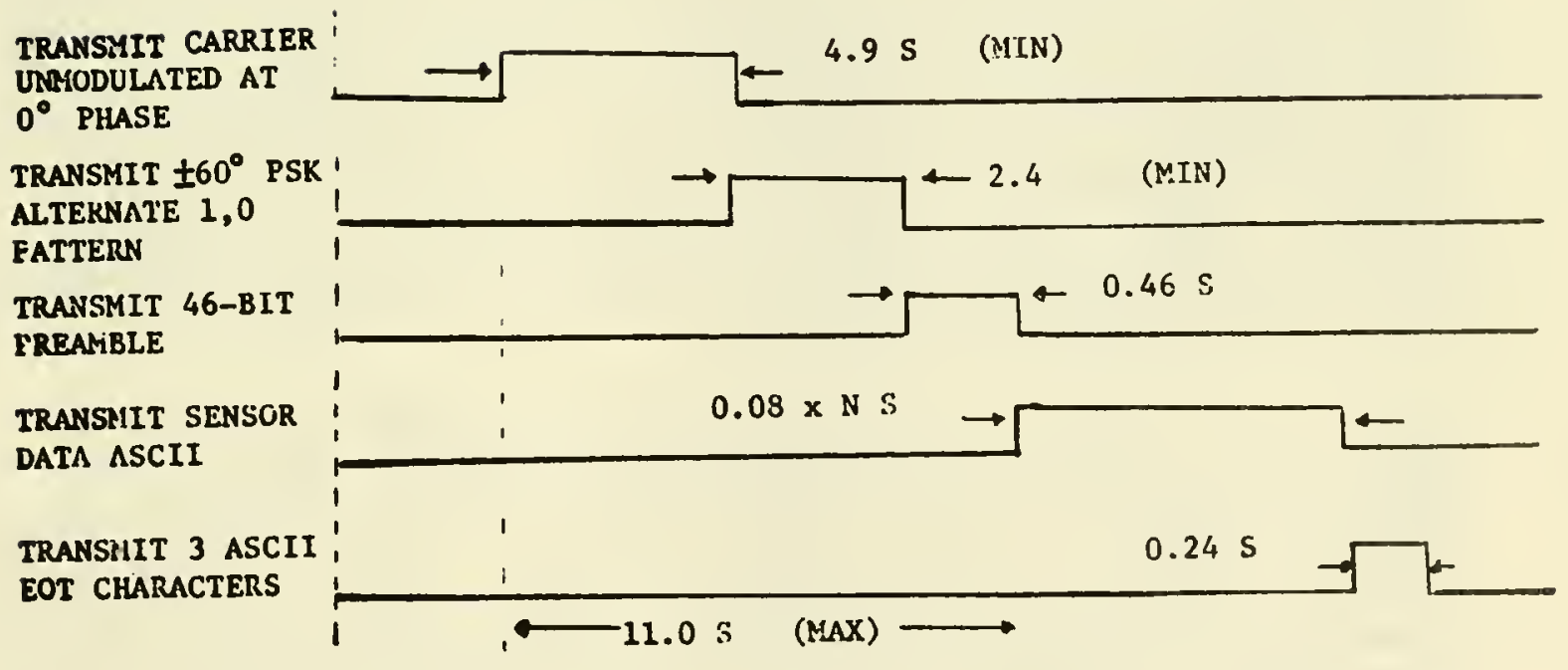

nOTE: $N$ - NURIBER OF 8-BIT ASCII CHARACTERS OF SENSOL DATA

Figure 7.--Platform Transmitter Response Timing. 
character. If necessary binary data may be transmitted when formatted into pseudo-ASCII characters, as shown in Figure 5. These special requirements are needed to ensure that binary data are not misinterpreted as control characters, affecting communications link operation.

The sensor data must not contain certain ASCII characters that have special control functions in the DCS dissemination system. These prohibited characters are: DLE, NAK, SYN, ETB, CAN, GS, RS, SOH, STX, ETX, ENQ, and ACK. EOT characters must appear only at the end of transmission and will be deleted from the data prior to dissemination. Data characters containing parity errors will be replaced with NUL or $\$$, depending on the specified dissemination link.

\subsubsection{Sensor Platform Transmitter Response Format}

The platform response format satisfies the CDA requirements for response signal acquisition, clock recovery, data bit synchronization, message synchronism, and optimum response channel

utilization. The data are Manchester encoded to provide a selfclocking signal which is used to modulate the transmitted carrier by phase shift keying (PSK). Figure 6 defines the coding and modulation characteristics of the platform transmitter response signal.

A platform response transmission (Figure 7) begins with unmodulated carrier ( $O^{\circ}$ phase shift) for 5 seconds to allow the CDA data demodulator to acquire the signal and establish a phase reference. Next, the response signal is PSK'd with $2 \frac{1}{2}$ seconds of alternate "one," "zero" data (Manchester coded) so the data demodulator may obtain the $100-\mathrm{Hz}$ bit rate clock and data bit synchronization. Then the 46-bit preamble is sent, consisting of the 15-bit MLS message sync word (100010011010111) followed by the 31-bit sensor platform address identifier word with the most significant bit (MSB) of those sequences transmitted first. The sensor data in serial ASCII character (odd parity) format are sent immediately following the preamble with the least-significant bit of each character transmitted first. A postamble consisting of 3 8-bit EOT characters marks the end of the response message.

The CDF considers all the data in the platform response message framed by the preamble and postamble to be sensor data characters in ASCII. At the CDA, the received platform address identifier is compared with the expected address identifier obtained from the CDF computer, and the sensor data characters are tested for errors by examining received character parity. Detected error conditions will cause the appropriate error status to be transmitted along with the sensor data to the CDF computer. If no response is received at the CDA when one is expected, a "no message received" notice is sent to the CDF computer and on to the user.

\subsubsection{Command/Interrogate Signal Format}

The signal transmitted from the CDA to the deployed sensor platform field via the spacecraft transponder contains two information items: 


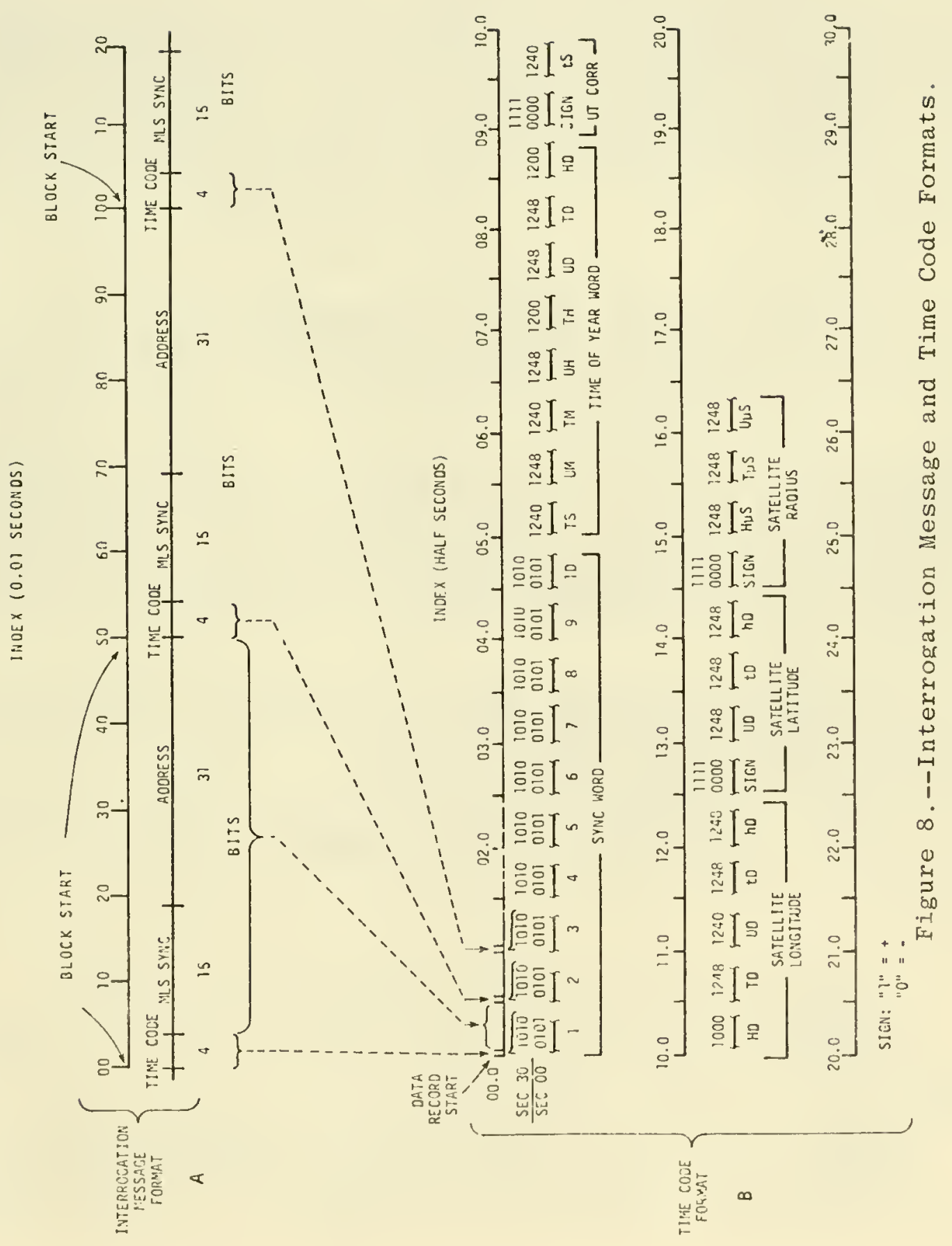


(1) Platform address identifier (or command word) which initiates the appropriate response activity from the platform to which it corresponds.

(2) Coded time data, updated at $\frac{1}{2}$-minute intervals, referred to an NBS source.

The CDA equipment which generates the Interrogate signal transmits a different frequency for each spacecraft; a sensor platform receiver must be equipped to receive the specific signal frequency transmitted via the spacecraft serving its site. Currently, both spacecraft transmit identical address identifiers. The Interrogate signal modulation characteristics are those shown previously in Figure 6 .

The Interrogate message is formatted into blocks of 50 bits, as follows:

(1) 4 bits of time-code data.

(2) 15-bit MLS for message sync; same as used in platform reply (paragraph 2.2.2).

(3) 31-bit address identifier.

Message timing is derived from the CDA station atomic clocks which are maintained by NBS to within a few microseconds of the master NBS clock in Boulder, Colorado. As an approximate accommodation of the satellite transmission path time delay, the time signals as provided to the CDA Interrogate signal generating equipment are advanced 260,000 microseconds. The leading edge of the first bit of each message block coincides with the CDA station standard's $\frac{1}{2}-$ second mark.

A complete time-of-year data record is transmitted piecemeal in the time code bits every 30 seconds, beginning on the minute-and $\frac{1}{2}$-minute marks. Figure 8 shows the format of the Interrogate message block and the time code record.

The serial bit transmission sequence is shown in real-time reading from left to right. In all message segments the LSB is sent first.

The format of the time-of-year data record is as follows:

(1) Sync word, 40 bits in length, consisting of ten 4-bit time code characters which designate whether the transmission began on the minute-or $\frac{1}{2}$-minute mark. (1010 character for 1-minute records, 0101 for $\frac{1}{2}-$ minute records; LSB sent first).

(2) Time-of-year word as eight 4-bit time code characters with the hexadecimal value of each character representing a decimal digit of the sequence; seconds (tens); minutes (units), (tens); hours (units), (tens); days (units), (tens), (hundreds), of Coordinated Universal Time (UTC). 
(3) Correction to universal time as 2 time code characters; sign of correction $(1111=+, 0000=-)$, and tenths of seconds corrected.

(4) Satelite ephemeris in geocentric measure as thirteen 4bit time code characters; longitude in degrees (hundreds), (tens), (units), (1/10's), (1/100's); latitude in degrees (sign), (units), (1/10's), (1/100's), orbital radius correction in microseconds (sign), (hundreds), (tens), (units).

NBS Technical Note 681, "A Satellite-Controlled Digital Clock," describes use of the time code data transmitted via the DCS Interrogate signal to obtain continuously updated time-of-year data at a sensor platform site to an accuracy of about 100 microseconds with $+20-$ microsecond precision.

\subsubsection{Platform Radio Set Characteristics}

A sensor platform does not need to be equipped to receive the Command/Interrogate signal for operation in the DCS. The additional flexibility provided by the Command/Interrogate capability may be desirable, for example, when the data reporting schedule requires modification or when the sensor activities must be directed remotely.

The requirements for a sensor platform radio set are described in NOAA/NESS Specification No. 200.004, "Data Collection Platform Radio Set Specification." The design characteristics of platform radio sets essential to operation in the DCS are presented in Appendix C, "Platform Radio Set Certification Requirements."

\subsubsection{Environmental Considerations}

Efficient utilization of the DCS capability for timely data collection from unattended sensor sites requires that platform radio sets be able to operate within specifications for all environmental conditions to which they are exposed. Environmentally induced performance changes may result in loss of important data from the affected sensor platform, as well as from other platforms which experience interference produced by the malfunctioning equipment.

\subsection{Spacecraft Function in the DCS}

\subsubsection{Communication Transponder}

The spacecraft (GOES) operates as a cross-strapped transponder within the DCS communications chain. Command/Interrogate signals from the CDA station are received by the spacecraft at $\mathrm{S}$-band, then translated to UHF and retransmitted through an Earth-coverage antenna to the field of deployed sensor platforms. Response signals from the sensor platform sites are received by the spacecraft at UHF, translated to S-band, and sent to the CDA Station. The spacecraft transponder is fully redundant to guard against DCS outages, because of premature equipment failure. 


\subsubsection{Conditions Affecting Access and Performance}

Periodic preventive maintenance is scheduled for the DCS we11 in advance, since no interrogated data collection can be carried out during these periods.

Twice each year, the Earth's position will be such that the spacecraft orbit carries it through the Earth's shadow. Because the spacecraft's prime power source is a solar array, safety considerations may require the transponder to be operated in a low-power mode if at all to conserve secondary power. This results in a satellite transmitter power drop of from 1 to $3 \mathrm{~dB}$.

DCP up-link response signals, occasional TIROS-N data relay signals, and satellite receiver noise share the down-link power output of the GOES. Increasing the number of active DCP channels thus decreases the power per channel, and also simultaneously reduces the down-link noise. Until the noise contributed by the CDA or other ground terminal receiving system becomes the limiting factor, the net signalto-noise ratio is nearly independent of channel loading, and bit error probabilities of less than $10^{-5}$ may be anticipated, as described in paragraph 1.2 .9 on page 8 .

\subsection{Command and Data Acquisition}

\subsubsection{Response Data and Command/Interrogate Signals}

A UHF Pilot Response signal centered in the platform response frequency band and derived from the CDA station frequency standard is transmitted to the spacecraft transponder along with replies from the deployed platforms. The corresponding signal received at the CDA station is recovered from the $S$-band receiver. The recovered signal is applied to the response link receiver. The recovered signal is applied to the response link Automatic Phase Control and Multicoupler Chassis which compensates for spacecraft oscillator variations, and divides the received CDA response signals in order to drive the response channel data demodulators. Forty data demodulators are presently implemented with the capacity to expand at a future date. 
Command/Interrogate data are applied to the Interrogate Channel Modulator which Manchester encodes the data and applies them to a Phase Shift Keying (PSK) modulator. The modulator output provides the input to the Interrogate Channel Frequency Control, which supplies the CDA S-band transmitter with the Interrogate Signal for transmission to the spacecraft transponder. The UHF Command/Interrogate signal is received at the CDA and applies to the Interrogate Channel Data Demodulator which produces an error signal for automatic frequency control and demodulates the Interrogate signal for bit error rate performance testing. (See Figure 3, page 19.)

\subsubsection{Time Data and Command/Interrogate Signal Format}

Details of the modulation and data contained within the Command/ Interrogate signal are presented in paragraph 2.2.3. Since a Command/Interrogate signal is transmitted continuously, a dummy address is utilized in those periods when the CDF is not providing platform addresses for interrogation. In the absence of any address identifiers from the CDF for transmission to the sensor platform field, an idle pattern of 31 binary bits is used (00110100100001011101100011111). These bits are Manchester encoded and transmitted MSB first.

\subsubsection{Response Data Demodulation and Transmission to CDF}

After recovery of the response signals as described in paragraph 2.4 .1 , the response data are demodulated in the appropriate CDA Channel Data Demodulator and held in buffer storage until the entire response is received at the CDA. The response address identifier is compared at the CDA with the expected platform address, and the message characters are checked for parity errors. The platform sensor response and any applicable error conditions are then forwarded to the CDF for logging and dissemination, or for special attention based on error conditions. 
Engineering tests of SMS-2 (op. cit.) showed that the average time delay of platform site interrogation (from transmission of address identifier to reception of response preamble) was 12.6 seconds.

\subsection{Data Recovery-Central Distribution Facility (CDF)}

\subsubsection{Recovered Data Characteristics}

Recovered data and other messages sent from the CDF to the users are in data record form, consisting of a heading and sensor platform data. Each record represents one of the following:

(1) Platform sensor response.

(2) Abnormal platform response message.

(3) Operator message.

(An "abnormal platform response message" is a "canned" message from the DPS describing an unexpected event in a platform response, and is preceded by two carets $(\Lambda \Lambda)$ for rapid identification.)

Each normal platform response data record contains:

(1) The platform sensor address identifier (in hexadecimal representation).

(2) A question mark (?) if the address had bit errors or a space if the address was received without error.

(3) The time platform data were received, as day-of-year ( 3 characters), hour ( 2 characters), minute ( 2 characters) and second ( 2 characters) of Coordinated Universal Time.

(4) Received data (as ASCII characters).

Characters received with parity errors will be replaced in the data with either a dollar sign (\$) or NUL character, depending on the means of dissemination as explained in 2.5 .3 below. The EOT characters required to terminate the platform transmission are not included with data in the record. (For further details regarding this general subject, refer to the user interface manual listed in the references.)

\subsubsection{Error Checks and Abnormal Responses}

The CDF identifies as abnormal all responses with error conditions. All scheduled response messages will be routed to users even if the address is received in error. (Only unscheduled unrecognizable messages will not be disseminated.) 
The following error conditions are recognized in the CDF:

(1) A scheduled or interrogated message is not received when expected.

(2) A scheduled message is received slightly off schedule.

(3) An unscheduled response message is received (4)

(4) An interrogation was not performed as scheduled for some reason.

(5) A response message exceeded the expected channel occupancy time for the sensor platform.

(6) Data are received with parity errors. (For interrogated responses, the user may specify whether all responses are required, or only those without error. The maximum number of reinterrogations to recover bad data (up to 15) may also be specified.).

(7) Address identifiers received with 2 or fewer bit errors will be corrected within the data record by the CDF.

2.5.3 User Access to Recovered Data

\subsubsection{User Dissemination Circuits}

Three classes of communication circuits are utilized by the CDF for dissemination of sensor platform data. These classes differ mainly in the user terminal capabilities the CDF presumes to exist, and their respective information transfer rate. The three classes of circuits are:

(1) Full-time, dedicated.

(2) 1200 baud dial-up.

(3) 110 baud dial-up.

\subsubsection{Dedicated Circuit}

For the first class of circuit, the CDF uses synchronous data transmission at modulation rates (determined by the modem equipment) up to 9600 baud. The "handshaking" protocol between the CDF and user terminal follows the IBM Binary Synchronous Communication procedures ("General Information, Binary Synchronous Communications," IBM No. 6A2730042). Communication over the dedicated, full-time circuits of the CDF has the following characteristics: 


$\begin{array}{ll}\text { Channel Type } & \text { full duplex; half-duplex protocol } \\ \text { Modulation Rate: } & 0-9600 \text { baud; } 2400 \text { baud nominal } \\ \text { Coding } & \text { ASCII, odd parity, nontransparent } \\ \text { Error Control }: & \text { block transmission; alternating ack } \emptyset, \\ \text { ack } 1 & \text { l90 data characters maximum and } 3 \text { (or } 4) \\ \text { Block Length } & \begin{array}{l}\text { framing characters } \\ \text { user option of Longitudinal }\end{array} \\ \text { Block Check } & : \begin{array}{l}\text { Redundancy Check (LRC) or Cyclic } \\ \text { Redundancy Check (CRC-16) }\end{array}\end{array}$

Because the full-time circuits are permanent connections, the CDF knows which user is associated with each, and there is no need for identification procedures. If any platforms have emergency transmission capability, the CDF may identify such transmissions with a special header (optional) and data description in the disseminated data bulletin. ${ }^{2}$ operator intervention is not required for routine or emergency data dissemination over a full-time dedicated circuit.

The bulletin format used contains the following information sequence:

\begin{tabular}{|c|c|c|}
\hline & Function & Characters \\
\hline & Control character ( $\mathrm{SOH})$; start of heading & 1 \\
\hline 5 & 3-digit message sequence number & 3 \\
\hline & Catalog number; identification of user & 5 \\
\hline$\sqrt{7}$ & Control character (STX); start of text & 1 \\
\hline 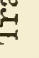 & 6-digit data description; user constant & 6 \\
\hline & Space character & 1 \\
\hline & $\begin{array}{l}\text { 2-digits each; day of month, hour, minute of } \\
\text { dissemination }\end{array}$ & 6 \\
\hline & DUP; Space, indicates possibly duplicate bulletin & 4 (Optional) \\
\hline & End-of-line; carriage return, 1 inefeed & 2 \\
\hline
\end{tabular}


Function

Number of

Characters

Control character (RS); record separator identifies start of platform replies

Sensor platform address identifier

? or space; shows whether address was correct or not

Date-time of reception; \# day of year, hour, minute, and second

Platform data; without final EOT characters

Control characters (RS); separates platform replies within bulletin

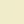

(1)

9

1

Next reply follows, as above, from "Sensor Platform address identifier."

Bulletins are segmented into uniform length blocks for transmission. Bulletins are generally less than 10 full blocks; the only exception being when a report beginning in the ninth block spans one or more blocks. Each block is formatted as follows:

Control character; start of transmission block (SOH or STX)

Message characters 190

Control character; end of transmission block (ETB or ETX)

Block error control character; LRC (or CRC-16) 1 (or 2)

NOTES :

(1) Start of transmission block character is $\mathrm{SOH}$ for initial block, STX for subsequent blocks.

(2) End of transmission block character is ETB for initial blocks, ETX for final block.

(3) Final block may have 1 to 190 message characters

(4) Block error control character: if longitudinal. redundancy check ( $L R C$ ), it is composed to the MOD-2 sum of corresponding character bit positions of all. characters following the start of transmission block character, except that its parity bit is odd parity; if cyclic redundancy check (CRC-16), it is the 16-bit remainder after division of the message characters (following the start of transmission block character) by the polynominal $x^{16}+x^{15}+x^{2}+1$. 


\subsubsection{1200 Baud DDD Circuit}

The second class of circuit (1200 baud dialup) has the following characteristics:

Channel Type : DDD subscriber lines; half-duplex, AT\&T type $202 \mathrm{C}$ modem or equivalent

Modulation Rate: 1200 baud (120 characters/s)

Coding : asynchronous ASCII (10 bits) even parity

Error Control : block transmission: ACK/NAK

Block Length : 320 (max) data characters, and 6 framing characters with 6 device control characters

Block Check

Character : Longitudinal Redundancy Check (LRC)

NOTE: CDF assumes user terminal on 1200 baud circuits to have the characteristics of a Texas Instruments Model 742, with options:

(1) "Auto-answer" line discipline.

(2) "Answer-back memory" preprogramed with user ID.

(3) Bell 202C data set compatible modem.

The TI Model 742 can transmit and receive at 120 characters per second (CPS), but its printer operates only up to 30 CPS. The CDF uses control character sequences to remotely command the terminal recorder and printer. Table 3 lists the possible commands. The platform sensor data are disseminated at 120 characters per second rate with the terminal's printer OFF. An end-of-line (carriage return, line feed) is inserted following every 80 data characters by the CDF.

TABLE 1

TI 742 COMMAND CHARACTERS

Command

Record ON

Playback OFF

Printer ON

Printer OFF

Auto Device Control ON (ADC ON)

Auto Device Control OFF (ADC OFF)
Code

*DC2

*DC3

*DLE 9

*DLE 0

*DLE :

$* \mathrm{DLE} ;$

(*) Utilized by DPS/DCS. 
The following procedures are employed for user-CDF communications over 1200 baud dialup circuits:

Procedures on $1200-$ bps Line

(1) Utilizing a Texas Instruments Model 742 (or equivalent) terminal, the user dials the telephone number for the 1200-bps line.

(2) The CDF answers the cal1, and when the answer tone sounds the user presses the DATA button or pushes down the exclusion key.

(3) The CDF waits 8 seconds from occurrence of the ring to permit the terminal to identify itself by automatically triggering its answer-back device. (If the terminal is equipped with an answer-back device, it must be programed to transmit either STX, user ID, ETX, LRC, or STX, user ID, "DIS," ETX, LRC. The correct LRC must be hand computed and preprogramed for for the answer-back, since normally it is not generated automatically in this situation.)

(4) If the CDF receives no identification within 8 seconds, it transmits the message:

\section{DCS/CDF. ENTER ID}

The user will sign on by responding with the framing character STX followed by the user ID (a maximum of six characters), and the framing character ETX. Optionally, he may enter STX, user ID, a comma, and one of the following: MSG, DIS, RLT. If DIS or RLT is specified the GMT (in the format DDDHHMMSS) may be included. All entries must be terminated by ETX and LRC.

(5) For either answerback or manual sign-on messages, CDF determines whether the ID is valid; and if only the ID was entered, determines whether any new message data have been acquired since the previous user inquiry (6).

(6) If the ID is invalid, the request is repeated up to five times, after which the CDF goes on-hook after sending the following message:

\section{TOO MANY ERRORS}

(7) If the ID is correct, and if only the ID was entered, $C D F$ informs the user of the number of messages received since the previous inquiry and the time of the last dissemination. The CDF then transmits:

ENTER MSG, DIS, RLT, OR STOP. 
(7a) MSG Directive - the user may transmit a text message to the DCS operator (to be displayed on the console) by entering STX MSG ETX after the CDF informs him/her of the number of messages received since the previous inquiry (or by entering MSG following the user ID in the sign-on, separated by a comma). The CDF responds with STX ENTER MESSAGE ETX, after which the user may enter the message.

(7b) DIS Directive - the user may request transmission of the sensor platform data by entering STX DIS ETX after the CDF informs $\mathrm{him} / \mathrm{her}$ of the number of messages received since the previous inquiry (or by entering DIS following the user ID in the sign-on, separated by a comma).

Transmission of sensor platform data, if requested, begins with the oldest undisseminated message and continues to the newest message on the user's queue.

Abnormal platform response messages are transmitted in lieu of data when appropriate, and are identified by two carets $(\Lambda \Lambda)$ preceding the text of the message.

Alternatively, the user may specify a new time (other than "time of last inquiry") from which dissemination of data in the queue may begin, by entering STX DIS DDDHHMMSS ETX in GMT (or UTC).

(7c) RLT Directive - the user may request transmission of sensor platform data acquired after a specified time for information only, by entering STX RLT, DDDHHMMSS ETX after the CDF informs him/her of the number of messages received since the previous inquiry. As in ( $7 \mathrm{~b}$ ) above, a new time interval may be specified to begin playback. Data disseminated by this method are not recorded by the CDF.

(8) Once transmission of the most recent sensor platform data (DIS only) has been completed, the CDF sends the following message:

\section{NNN MESSAGES DISSEMINATED.}

VERIFY: OK, NO, OR STOP.

If the user enters OK, after DIS (dissemination) the UTC of the last message disseminated will be inserted into the user Queue Table as the "last time of dissemination" (for use the next time he/she calls.) The "number of messages" will be reset to zero, and the message pointers updated. If the user enters NO, then the user Queue Table will not be updated. After either OK or NO, the CDF solicits a new request with the following message:

ENTER MSG, RLT, DIS, OR STOP. 
If at any time the user enters STOP, the CDF sends an EOT and goes on-hook. If the user hangs up without answering STOP, the CDF will assume that the previously transmitted data were successfully disseminated.

(9) If the user disconnects the circuit prior to transmission of all the messages, then the CDF considers that no messages have been disseminated.

(10) Data transmitted on these circuits have all erroneous characters (containing parity errors) replaced with a dollar sign (\$).

(11) If the CDF receives STX CAN ETX LRC from the terminal, signifying a playback error (cassette I/O error), it will send the following message to the user:

\section{PLAYBACK ERROR. TRY AGAIN.}

The user will be able to reenter his request.

\subsubsection{110-Baud DDD Circuit}

The third class of circuit (110 baud dial-up) has the following characteristics:

$$
\begin{array}{ll}
\text { Modem } & \text { AT\&T Model } 103 A 3 \\
\text { Channel Type } & \text { DDD subscriber lines; half-duplex } \\
\text { Modulation Rate: } & 110 \text { baud ( } 10 \text { characters/s) } \\
\text { Coding } & \text { Asynchronous ASCII ( } 11 \text { bits) even parity } \\
\text { Error Control : None }
\end{array}
$$

The CDF assumes that the terminal on a 110-baud dialup line is similar to a Teletype Model ASR-33. User communications over these low-speed lines require the following procedures:

Procedures on 110-baud Line

(1) Utilizing a terminal, the user dials the telephone number for the 110-baud Iine.

(2) The CDF automatically answers, and transmits the message:

DCS. ENTER ID 
(3) The answer-back capability available on many terminals will respond to the WRU. At terminals not thus equipped, the operator will respond with the user ID (a maximum of six characters). Optionally, he/she may enter his/her user ID, a comma, and one of the following: $\overrightarrow{M S G}$, DIS, RLT, or the time (in the form DDDHHMMSS of GMT).

(4) The CDF determines whether the ID is valid, and, if only the ID was entered, determines whether any new message data have been acquired since the previous user inquiry.

(5) If the ID is invalid, the request is repeated up to five times, after which the CDF goes on-hook after sending the following message:

\section{TOO MANY ERRORS.}

(6) If the ID is correct, and if only the ID was entered, CDF informs the user of the number of messages received since the previous inquiry and the time of the last dissemination. The CDF then transmits:

$$
\text { ENTER MSG, DIS, RLT, OR STOP. }
$$

(6a) MSG Directive - the user may transmit a text message to the DCS operator (to be printed on the console) by entering MSG after the CDF informs him/her of the number of messages received since the previous inquiry (or by entering MSG with the ID entry, separated by a comma). The CDF responds with ENTER MESSAGE, after which the user may enter the message.

(6b) DIS Directive - the user may request transmission of the sensor platform data by entering DIS after the CDF informs him/her of the number of messages received since the previous inquiry (or by entering DIS after the ID entry, separated by a comma).

Transmission of sensor platform data, if requested, begins with the oldest undisseminated message and continues to the newest message on the user's queue. Abnormal platform response messages are transmitted in lieu of data when appropriate, and are identified by two carets $(\Lambda \Lambda)$ preceding the test of the message.

Alternatively, the user may specify a new time (other than "time of last inquiry") from which dissemination of data in the queue may begin, by entering DDDHHMMSS (in GMT). 
(6c) RLT Directive - the user may request transmission of sensor platform data acquired after the connection is made until the user hangs up, by entering RLT after the CDF informs him of the number of messages received since the previous inquiry (or by entering RLT after the ID entry, separated by a comma). Optionally, RLT, DDDHHMMSS may be specified to receive data disseminated earlier. As in paragraph (7b), page 26, a new time interval may be specified to begin playback. Data disseminated by this method are not recorded by the CDF.

(7) Once transmission of the most recent sensor platform data has been completed, (DIS only) then CDF sends the following message:

\section{NNN MESSAGES DISSEMINATED.}

VERIFY: OK, NO, OR STOP.

If the user enters OK, the GMT of the last message disseminated will be inserted into the user queue table as the "last time of dissemination." The "number of messages" will be reset to zero, and the message pointers updated. If the user enters NO, then the user queue table will not be updated. After either OK or NO, the CDF solicits a new request with the following message:

$$
\text { ENTER MSG, RLT, DIS, OR STOP. }
$$

If at any time the user enters STOP, the CDF disconnects. If the user hangs up without answering STOP, the CDF will assume that the previously transmitted data were not successfully disseminated.

(8) If the user disconnects the circuit at his/her end prior to transmission of all his/her messages, then the CDF considers that no message has been disseminated.

(9) Data transmitted on these circuits have all erroneous characters (containing parity errors replaced with a dollar sign (\$). 


\section{REFERENCES}

Cateora, J.V., Davis, D.D., and Hanson, D.W., 1976. A Satellite Controlled Digital Clock. NBS Technical Note 681, Time and Frequency Division, Institute for Basic Standards, National Bureau of Standards, U.S. Department of Commerce, Boulder, Colorado, $46 \mathrm{pp}$.

GOES Data Collection System, SMS2 Test Report, Test Report TER-383-002 for Office of System Engineering, NOAA/NESS, by Telcom, Inc., Vienna, Virginia, $24 \mathrm{pp}$.

McManamon, P., 1973. GOES Data Collection System Performance Estimates. Telecommunications Technical Memorandum OTM73-125, Institute for Telecommunication Sciences, Office of Telecommunications, U.S. Department of Commerce, Boulder, Colorado, $66 \mathrm{pp}$.

User Interface Manual, NESS/NOAA/Department of Commerce, by GTE Information Systems, Systems Division, Silver Spring, Maryland, May $1978,50 \mathrm{pp}$. 


\section{APPENDIX A}

\section{USERS REQUEST QUESTIONNAIRE}

1. Describe fully your application

Operational/Experimental

If experimental, please complete the following:

Name and address of the funding agency Administrator.

Name and address of the party responsible for implementing your DCS program, i.e., the principal investigator.

Give the starting and ending dates of the period during which you plan to collect data via satellite.

Purpose of Data

Data Perishability

Final User of Data

2. Type of system

Interrogated

Self-time

Hybrid

3. Number of Platforms

Number of each Type

Number of Platforms with Emergency Alarm Provision

Time Scale for Deployment of each Type

4. Location of Platforms by Types

State, ocean

Nearest city if located in state

Fixed station - Latitude/Longitude

Mobile station operating area - Latitude/Longitude of Bounding Area

5. Data

Format of Data

Bits per Sensor Message

6. Reporting Times

Interrogation Schedule

Self-Timed Schedule

7. Data Delivery

Data Form

(Magnetic Tape, Paper Tape, Computer Printout, etc.)

Address for Delivery

How often required? (Delivery once per hour, per six hours, per day, etc.)

8. Explain why commercial services cannot meet your program needs.

9. Agency to install and maintain platform equipment. 



\section{APPENDIX B \\ MEMORANDUM OF AGREEMENT BETWEEN NOAA \\ AND THE USER}

\section{INTRODUCTION}

The National Environmental Satellite Service (NESS), of the National Oceanic and Atmospheric Administration (NOAA) hereinafter referred to as the operator (of the Synchronous Meteorological Satellite (SMS) and the Geostationary operational Environmental Satelite (GOES) and the Command and Data Acquisition (CDA) (Station)) and the (user) (agency), hereinafter referred to as the user (the provider of Data Collection Platforms and the user of the data collected) agree on the "Joint Understanding" below and agree to fulfill the undertakings specified.

I. Name of Program. The program to which this Memorandum applies shall be known as the "National Environmental Satelite Service (user) GoEs Data Collection System Program".

II. Joint Understanding.

A. To qualify for collection by' the GoEs, the data from the user's Data Collection Platforms must fall within the definition of environmental data. Environmental data are defined as observations and measurements of physical, chemical, or biological properties of the oceans, rivers, lakes, solid Earth and atmosphere (including space).

B. Authority for the GOES to utilize the radio frequency band 401.7 to $402.1 \mathrm{MHz}$ as an uplink and the radio frequency band 468.750 to $468.950 \mathrm{MHz}$ as a down link is contained in the Frequency Assignment Subcommittee/Interdepartment Radio Advisory Comittee docket numbers 7422556 and 7422589 , respectively. Docket number 7422556 grants the operator the authority to make frequency channels available to the user. However, it is understood that the user must obtain authority from appropriate national agencies to transmit on frequency channels, designated by the operator, within the uplink band. The operator will also provide address codes.

C. The operator will not assign a channel to one user for full time use; however, time periods within a channel will be assigned and on a priority basis.

D. The operator reserves the right to terminate or suspend the user's participation in this program in the event of spacecraft or ground equipment limitations requiring curtailment or elimination of services. 
E. Unless an exception is specified elsewhere in this memorandum, data collected for users shall be made available from NESS to other interested parties as appropriate.

F. Data Collection Platforms which the users plans to implement as part of the GOES Data Collection System are subject to certification by the operator before deployment.

G. In consultation with the user, the operator will establish the collection times and data lengths for the user's Data Collection platforms and the schedules and methods for data dissemination.

H. All transmissions from the Data Collection Platforms to the GOES spacecraft will be coordinated with the operator prior to such transmissions.

II. Undertaking by the user.

The user shall:

A. Provide the operator a list of the user's Data Collection Platforms showing the type (self-timed, interrogate); where each is to be located; and which platforms are equipped with emergency alarm provisions.

B. Provide the operator notification prior to Data Collection Platform relocation.

C. Provide the operator with the data type and message load planned for each Data Collection Platform.

D. Provide the personnel, funds, and equipment necessary to carry out the portion of the program at the Data Collection Platform location.

E. Operate and maintain the Data collection platforms in conformance with equipment performance standards as specified by the operator in: National Environmental Satellite Service Specification for Data Collection Platform Radio set (DCPRS). Specification No. 200.004, January $27,1975$.

F. Provide the personnel, funds and equipment necessary to operate and maintain facilities for receipt of collected data. These responsibilities include the cost of the communication interface at the NESS facility and the means to forward the data to the terminal point designated by the user. The communication interface is specified by the operator in: NESS GOES DCS User Terminal specifications, 1 January 1975.

G. Provide periodic reports, upon request from the operator, on the present application of the user's DCS data. 
IV. Specific Undertakings on the Part of the operator.

The operator shall:

A. Provide and operate the GOES spacecraft and the NESS ground facilities for receiving data collected from the satellite.

B. Provide telemetry reduction sufficient to monitor the user's Data Collection Platforms for meeting system performance standards.

C. Notify the user by the most expeditious means available whenever NESS system monitoring indicates the user's Data Collection Platform is performing outside system specifications or is inoperative.

D. Assign priorities for participation in the GOES DCS, scheduling purposes, channel assignments and for special DCS data requests according to the following categories in order of priority:

1. Disaster Warning

2. Operational

3. Experimental

E. Notify the user of modifications to the established operational schedule for collecting data from the user's Data Collection Platforms. Notification will be prior to activation of such schedule changes unless the operator must enact schedule modifications to provide services for emergency warnings. Sudden adverse spacecraft conditions may also preclude the operator from providing the user notification prior to schedule changes. In any event, notification will be made as soon as possible.

This agreement shall enter into force and effect for one year after signature by both parties and if otherwise consistent with applicable authorization and apprpriation Acts of Congress, this agreement shall remain in force and effect unless and until terminated at the election of either the user or the operator provided notification of such termination is in writing and forwarded by one party to the other, no less than 90 days in advance of termination.

Director, NESS

Date

User

Date 



\section{APPENDIX C}

DCPRS Certification Standards

(Interrogated \& Self-Timed)

1. RF Power Output. The Effective Isotropic Radiated Power (EIRP) of a DCPRS and antenna shall not exceed $50 \mathrm{dBm}$ under any combination of service conditions.

2. Frequency Characteristics. DCPRS received radio frequency (RF) shall be $468.825 \mathrm{MHz}^{1}$. The transmitter $\mathrm{RF}$ shall be in the $401.85 \mathrm{MHz}$ to $402 \mathrm{MHz}$ band. (See Table 1.)

3. Stability.

A. Temperature. The transmitter carrier frequency shall change by less than 0.5 parts per million over the temperature range of $-20^{\circ} \mathrm{C}$ to $+50^{\circ} \mathrm{C}$.

B. Long-Term. The long-term stability (including temperature variations) shall be better than one part per million per year.

C. Short-Term. The phase jitter on the transmit carrier shall be less than 3 degrees RMS.

4. Electromagnetic Interference (EMI). All transmitter spurious emissions, when measured with modulation and with antenna and diplexer connected, shall be down from the unmodulated carrier level by $50 \mathrm{~dB}$.

5. Transmission Format. After a minimum of 4.9 seconds of unmodulated carrier, the carrier shall be modulated with the bit and message synchronization patterns which are at least 2.4 seconds of alternate 1,0 data bits, and the 46bit preamble consisting of the 15-bit MLS sync word

followed by the 31 -bit $\mathrm{BCH}$ command word. Transmission of the address shall be complete within 11 seconds after receipt of an interrogation. The binary data shall be Manchesterencoded 8-bit ASCII, odd parity and shall modulate the carrier in the following manner: a data " 0 " shall consist of $+60^{\circ}\left(+5^{\circ}\right)$ carrier phase shift for 5 milliseconds followed by $-60^{\circ}\left(\mp 5^{\circ}\right)$ carrier phase shift for 5 milliseconds, and a data "l" shall consist of $-60^{\circ}\left(+5^{\circ}\right)$ carrier phase shift for 5 millisecunds followed by $+60^{\circ}\left(+5^{\circ}\right)$ carrier phase shift for 5 milliseconds. Data rate shal $\bar{I}$ be 100 BPS \pm .1 BPS. (See Figure 1.)

6. End of Transmission. Immediately after sending the sensor data, the DCPRS shall transmit three 8-bit ASCII, odd parity, End of Transmission (EOT) characters contiguously with the ASCII sensor data characters (no break) and return to the standby condition.

${ }^{1}$ For the West Satellite. DCPRS assigned to the East Satellite will be required to receive on $468.8375 \mathrm{MHz}$. 
7. Fail-Safe Design. The DCPRS shall incorporate a "fail-safe" design feature such that malfunctioning of the equipment shall in no way cause continuous transmission. Further, provision shall be made to retrigger the fail-safe via the interrogation link in 90-second intervals without interruption of data transmission by addressing the radio set.

8. Receive Signal. The DCPRS shall continuously receive and demodulate the standard GOES Data Collection System interrogation signal over an input signal level range of $-100 \mathrm{dBm}$ maximum to $-130 \mathrm{dBm}$ minimum centered at $468.825 \mathrm{MHz}^{2}$ and modulated $+60^{\circ} \mathrm{PSK}$ with $100-\mathrm{bit} / \mathrm{second}$ Manchester-coded data. The DCPRS shal1 be capable of simultaneous reception and transmission and meet all performance requirements of the DCPRS in this mode. The DCPRS shall be capable of automatically locking to the interrogation signal at an input signal level as low as $-135 \mathrm{dBm}$ (total signal power with the following data present: 15-bit Maximal Linear Sequence (MLS) sync word

(100010011010111) followed by the 31-bit Bose-Chaudhuri-Hocquenqhem (BCH) command word (0011010010000101011101100011111)).

9. Acquisition Time. The receiver shall acquire lock on the interrogation signal in 2 minutes or less from standby condition, when the carrier is within $100 \mathrm{~Hz}$ of $468.825 \mathrm{MHz}^{1}$.

10. Spurious Emissions. Reradiated local oscillator and mixing frequency signals shall be less than 50 microvolts at the antenna or primary power in-out terminal.

11. Antenna Polarization. Polarization shall be right-hand circular, according to IEEE Standard 65.34.159.

12. Data Formatting Restrictions.

The following ASCII control characters must not appear in the DCPRS message: DLE, NAK, SYN, ETB, CAN, GS, RS, SOH, STX, ETX, ENQ, and ACK. EOT characters may appear only at the end of transmission.

2 For the West satellite. DCPRS assigned to the East satellite will be required to receive on $468.8375 \mathrm{MHz}$. 
TABLE 1

INTERROGATED DCPRS TRANSMIT FREQUENCIES

\begin{tabular}{|c|c|c|c|}
\hline CHANNEL & FREQUENCY & CHANNEL & FREQUENCY \\
\hline 100 & 401.849569 & 150 & 401.924573 \\
\hline 101 & 401.851069 & 151 & 401.926073 \\
\hline 102 & 401.852569 & 152 & 401.927573 \\
\hline 103 & 401.854069 & 153 & 401.929073 \\
\hline 104 & 401.855569 & 154 & 401.930573 \\
\hline 105 & 401.857069 & 155 & 401.932073 \\
\hline 106 & 401.858569 & 156 & 401.933573 \\
\hline 107 & 401.860070 & 157 & 401.935073 \\
\hline 108 & 401.861570 & 158 & 401.936573 \\
\hline 109 & 401.863070 & 159 & 401.938074 \\
\hline 110 & 401.864570 & 160 & 401.939574 \\
\hline 111 & 401.866070 & 161 & 401.941074 \\
\hline 112 & 401.867570 & 162 & 401.942574 \\
\hline 113 & 401.869070 & 163 & 401.944074 \\
\hline 114 & 401.870570 & 164 & 401.945574 \\
\hline 115 & 401.872070 & 165 & 401.947074 \\
\hline 116 & 401.873570 & 166 & 401.948574 \\
\hline 117 & 401.875070 & 167 & 401.950074 \\
\hline 118 & 401.876570 & 168 & 401.951574 \\
\hline 119 & 401.878070 & 169 & 401.953074 \\
\hline 120 & 401.879571 & 170 & 401.954574 \\
\hline 121 & 401.881071 & 171 & 401.956074 \\
\hline 122 & 401.882571 & 172 & 401.957575 \\
\hline 123 & 401.884071 & 173 & 401.959075 \\
\hline 124 & 401.885571 & 174 & 401.960575 \\
\hline 125 & 401.887071 & 175 & 401.962075 \\
\hline 126 & 401.888571 & 176 & 401.963575 \\
\hline 127 & 401.890071 & 177 & 401.965075 \\
\hline 128 & 401.891571 & 178 & 401.966575 \\
\hline 129 & 401.893071 & 179 & 401.968075 \\
\hline 130 & 401.894571 & 180 & 401.969575 \\
\hline 131 & 401.896071 & 181 & 401.971075 \\
\hline 132 & 401.897571 & 182 & 401.972575 \\
\hline 133 & 401.899072 & 183 & 401.974075 \\
\hline 134 & 401.900572 & 184 & 401.975575 \\
\hline 135 & 401.902072 & 185 & 401.977076 \\
\hline 136 & 401.903572 & 186 & 401.978576 \\
\hline 137 & 401.905072 & 187 & 401.980076 \\
\hline 138 & 401.906572 & 188 & 401.981576 \\
\hline 139 & 401.908072 & 189 & 401.983076 \\
\hline 140 & 401.909572 & 190 & 401.984576 \\
\hline 141 & 401.911072 & 191 & 401.986076 \\
\hline 142 & 401.912572 & 192 & 401.987576 \\
\hline 143 & 401.914072 & 193 & 401.989076 \\
\hline 144 & 401.915572 & 194 & 401.990576 \\
\hline 145 & 401.917072 & 195 & 401.992076 \\
\hline 146 & 401.918573 & 196 & 401.993576 \\
\hline 147 & 401.920073 & 197 & 401.995076 \\
\hline 148 & 401.921573 & 198 & 401.996577 \\
\hline 149 & 401.923073 & 199 & 401.998077 \\
\hline
\end{tabular}





\section{SELF-TIMED DCPRS DESIGN REQUIREMENTS}

1. RF Power Output. The Effective Isotropic Radiated Power (EIRP) of a DCPRS and antenna shall not exceed $50 \mathrm{dBm}$ under any combination of service conditions.

2. Frequency Characteristics. The DCPRS transmitted RF shall be in the 401.7 - MHz to 401.85-MHz band. (See Table ].)

3. Stability.

A. Temperature. The transmitter carrier frequency shall change by less than 0.5 parts per million over the temperature range of $-20^{\circ} \mathrm{C}$ to $+50^{\circ} \mathrm{C}$.

B. Long-Term. The long-term stability (including temperature variations) shall be better than one part per million per year.

C. Short-Term. The phase jitter on the transmit carrier shall be less than $3^{\circ}$ RMS.

4. Electromagnetic Interference (EMI). All transmitter spurious emissions, when measured with modulation and with antenna and diplexer connected, shall be down from the unmodulated carrier level by $50 \mathrm{~dB}$.

5. Transmission Format. After a minimum of 4.9 seconds of unmodulated carrier, the carrier shall be modulated with the bit and message synchronization patterns which are at least 2.4 seconds of alternate 1 , 0 data bits, and the 46-bit preamble consisting of the 15-bit MLS sync word followed by the 31-bit BCH command word. Maximum duration of this preamble shall be 9.0 seconds. The binary data shall be Manchester-encoded 8-bit ASCII, odd parity, and shall. modulate the carrier in the following manner: a data " 0 " shall consist of $+60^{\circ}\left(+5^{\circ}\right)$ carrier phase shift for 5 milliseconds followed by $-60^{\circ}\left(+5^{\circ}\right)$ carrier phase shift for 5 milliseconds, and a data "l" shall consist of $-60^{\circ}$ carrier phase shift for 5 milliseconds followed by $+60^{\circ}$ carrier phase shift for 5 milliseconds. Data rate shall be 100 BPS +0.1 BPS. (See Figure 1.)

6. End of Transmission. Immediately after sending the sensor data, the DCPRS shall transmit three 8-bit ASCII, odd parity, End of Transmission (EOT) characters contiguously with the ASCII sensor data characters (no break) and return to the standby condition.

7. Fail Safe Design. The DCPRS shall incorporate a "fail-safe" design feature such that malfunctioning of the equipment shall in no way cause continuous transmission.

8. Antenna Polarization. Polarization shall be right-hand circu1ar, according to IEEE Standard 65.34.159. 
9. Data Formatting Restrictions.

The following ASCII control characters must not appear in the DCPRS message: DLE, NAK, SYN, ETB, CAN, GS, RS, SOH, STX, ETX, ENQ, and ACK. EOT characters may appear only at the end of transmission.

10. The DCPRS reporting time shall always be within 30 seconds of its assigned reporting time. 
TABLE 1

SELF-TIMED DCPRS TRANSMIT FREQUENCIES

\begin{tabular}{|c|c|c|c|}
\hline Channel & Frequency & Channel & Frequency \\
\hline 1 & 401.700996 & 50 & 401.774450 \\
\hline 2 & 401.702495 & 51 & 401.775949 \\
\hline 3 & 401.703994 & 52 & 401.777449 \\
\hline 4 & 401.705493 & 53 & 401.778948 \\
\hline 5 & 401.706992 & 54 & 401.780447 \\
\hline 6 & 401.708491 & 55 & 401.781946 \\
\hline 7 & 401.709990 & 56 & 401.783445 \\
\hline 8 & 401.711489 & 57 & 401.784944 \\
\hline 9 & 401.712989 & 58 & 401.786443 \\
\hline 10 & 401.714488 & 59 & 401.787942 \\
\hline 11 & 401.715987 & 60 & 401.789441 \\
\hline 12 & 401.717486 & 61 & 401.790940 \\
\hline 13 & 401.718985 & 62 & 401.792439 \\
\hline 14 & 401.720484 & 63 & 401.793938 \\
\hline 15 & 401.721983 & 64 & 401.795437 \\
\hline 16 & 401.723482 & 65 & 401.796936 \\
\hline 17 & 401.724981 & 66 & 401.798435 \\
\hline 18 & 401.726480 & 67 & 401.799935 \\
\hline 19 & 401.727979 & 68 & 401.801434 \\
\hline 20 & 401.729478 & 69 & 401.802933 \\
\hline 21 & 401.730977 & 70 & 401.804432 \\
\hline 22 & 401.732476 & 71 & 401.805931 \\
\hline 23 & 401.733976 & 72 & 401.807430 \\
\hline 24 & 401.735475 & 73 & 401.808929 \\
\hline 25 & 401736974 & 74 & 401.810428 \\
\hline 26 & 401.738473 & 75 & 401.811927 \\
\hline 27 & 401.739972 & 76 & 401.813426 \\
\hline 28 & 401.741471 & 77 & 401.814925 \\
\hline 29 & 401.742970 & 78 & 401.816424 \\
\hline 30 & 401.744469 & 79 & 401.817923 \\
\hline 31 & 401.745968 & 80 & 401.819422 \\
\hline 32 & 401.747467 & 81 & 401.820922 \\
\hline 33 & 401.748966 & 82 & 401.822421 \\
\hline 34 & 401.750465 & 83 & 401.823920 \\
\hline 35 & 401.751964 & 84 & 401.825419 \\
\hline 36 & 401.753463 & 85 & 401.826918 \\
\hline 37 & 401.754962 & 86 & 401.828417 \\
\hline 38 & 401.756462 & 87 & 401.829916 \\
\hline 39 & 401.757961 & 88 & 401.831415 \\
\hline 40 & 401.759460 & 89 & 401.832914 \\
\hline 41 & 401.760959 & 90 & 401.834413 \\
\hline 42 & $401.7-2458$ & 91 & 401.835912 \\
\hline 43 & $401 . \quad \therefore 957$ & 92 & 401.837411 \\
\hline 44 & 401 . ๙5456 & 93 & 401.838910 \\
\hline 45 & 401.766955 & 94 & 401840409 \\
\hline 46 & 401.768454 & 95 & 401.841908 \\
\hline 47 & 401.769953 & 96 & 401.843408 \\
\hline 48 & 401.771452 & 97 & 401.844907 \\
\hline \multirow[t]{2}{*}{49} & 401.772951 & 98 & 401.846406 \\
\hline & & 99 & 401.847905 \\
\hline
\end{tabular}




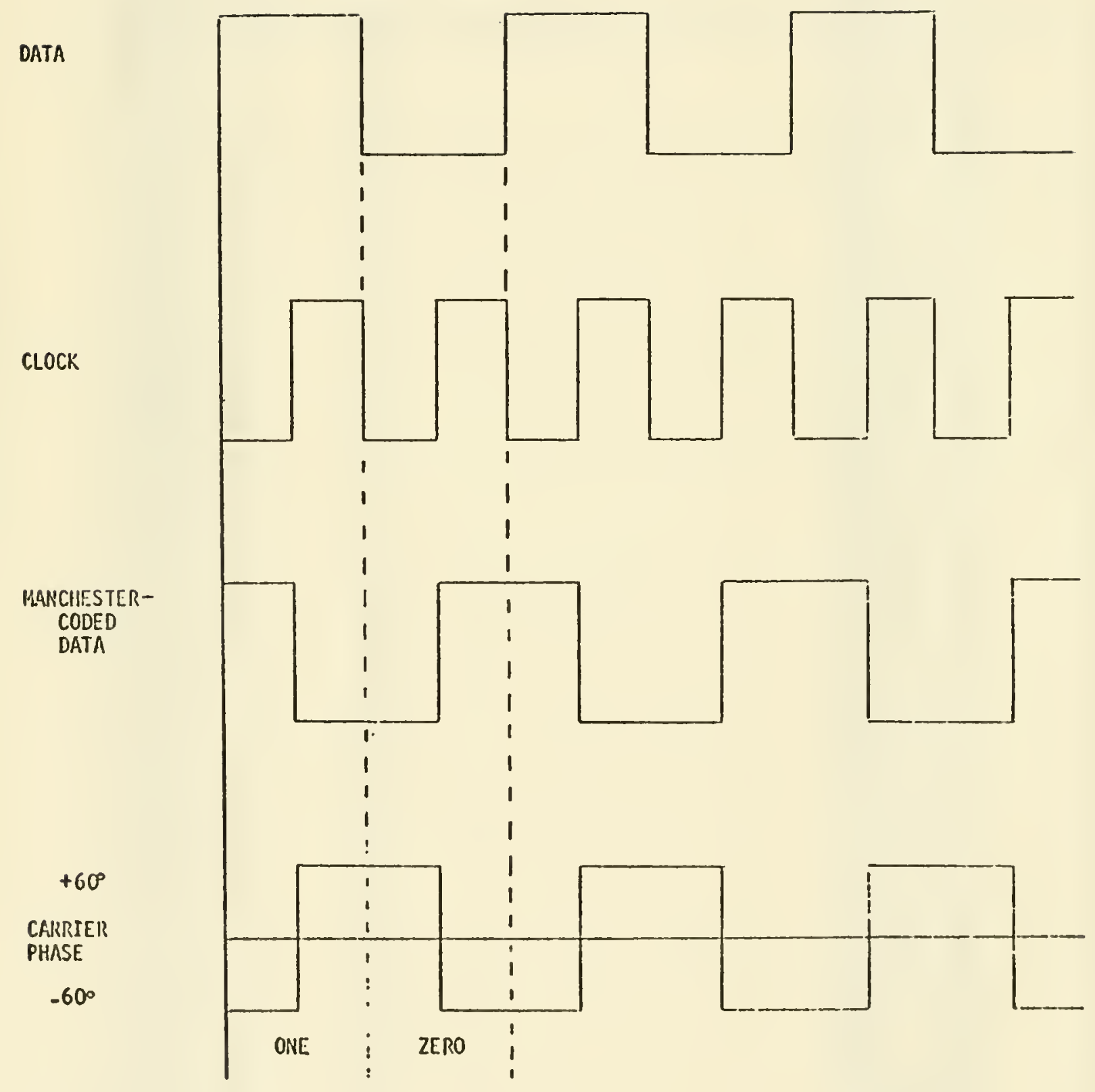

Figure 1.--Modulation Definition. 


\section{APPENDIX D}

SOME CONSIDERATIONS IN THE DESIGN AND INSTALLATION OF A RECEIVING SYSTEM TO RECEIVE DCS DATA DIRECTLY FROM THE SMS/GOES FAMILY OF SATLLLITES

December 1978

Prepared by:

JOHN J. NAGLE

Office of System Engineering National Environmental Satellite Service National Oceanic and Atmospheric Administration Washington, D.C. 20233 
CONTENTS

I. Introduction $\ldots \ldots \ldots \ldots \ldots \ldots \ldots \ldots \ldots \ldots \ldots \ldots \ldots \ldots$

II. Equipment needed for a typical DCS

direct readout station ..................... 48

III. DCS signal power $\ldots \ldots \ldots \ldots \ldots \ldots \ldots \ldots \ldots \ldots \ldots \ldots \ldots \ldots \ldots \ldots$

IV. Antenna/receiver considerations ................ 54

V. Demodulator/decoder $\ldots \ldots \ldots \ldots \ldots \ldots \ldots \ldots \ldots \ldots$

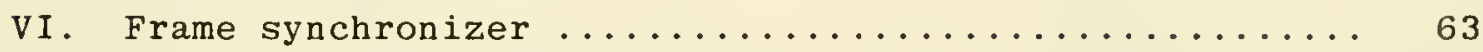

VII. Data processing equipment $\ldots \ldots \ldots \ldots \ldots \ldots \ldots$

VIII. Obtaining a direct readout receiving

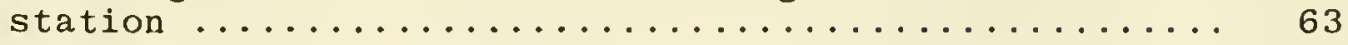

IX. Costs $\ldots \ldots \ldots \ldots \ldots \ldots \ldots \ldots \ldots \ldots \ldots \ldots \ldots \ldots \ldots \ldots$

APPENDIX A. Per-channel signal energy as a function of the number of active channels

APPENDIX B. Calculation of the phase modulation introduced by the switched array antenna 
ABSTRACT. The equipment needed to establish a readout receiving station for the Data Collection System (DCS) is discussed in general terms. The parameters and characteristics of the DCS are described as trey affect ground station equipment design.

\section{INTRODUCTION}

The SMS/GOES ${ }^{l}$ family of meteorological satellites provides, along with other capabilities, a DCS to relay in situ environmental data ubtained from a variety of sensors located in remote areas.

Typical sensors measure hydrologic, oceanographic, meteorological, ind other types of environmental parameters.

The National Environmental Satellite Service (NESS) provides ground faciliiies to receive the data transmitted to the satellite from the user's ground-based sensors and makes these available to users at the World Weather Building, Camp Springs, Maryland. DCS users must surply the ground communication link between their own facilities and Camp springs.

Under sorie circumstances, users may wish to provide their own satellite ground receiving station facilities.

The equipment needed to receive DCS data directly from the satelite is both sophisticated and expensive; ordinarily this expense cannot be justified except where the communications links between the user and Camp Springs, Maryland, are long and expensive or where the time required to establish these links can compromise the usefulness of the data. Another consideration is that some emergency situations, e.g., floods, that the platforms are designed to monitor may destroy land line communication circuits from NESS to the user's processing facility. Further complicating the picture is the fact that a number of design tradeoffs are possible, so that there is no single optimum choice of equipment.

This report lists some of the parameters of the DCS system and describes the manner in which they affect the components of a satellite receiving system. It is assumed that the reader has a basic knowledge of physics and some experience with satellite receiving systems.

For the purpose of this discussion, the description of the DCS will will be divided into six parts. The first of these, Part II, is a brief description of a typical station for receiving satelite data. Part II discusses the signal level available on the Earth's

\footnotetext{
${ }^{1}$ SMS stands for Synchronous Meteorological Satellite; GOES stands for Geostationary Operational Environmental Sateliite. The SMS satellites are prototypes for the GOES satellites.
} 
surface. Although this quantity is beyond the control of the user, if does determine the antenna and receiver noise temnerature

requirements.

The remaining four items--antenna/receiver, demodulator/decoder, frame synchronizer, and data processing equipment--are under the user's direct control and are discussed in parts IV, V, VI, and VII, respectively. A breakdown of the necessary equipment is shown in Figure 1.

\section{EQUIPMENT NEEDED FOR A TYPICAL DCS DIRECT READOUT STATION}

The equipment that must be provided by the user in order to receive DC replies directly is listed below:

\section{ANTENNA}

The antenna is usually paraboloidal and must be mounted on a supporting structure or building; it should have an unobstructed view of the satellite.

For normal operations, the ground station antenna is pointed at a sirigle satellite--GOES East or GOES West. As these satellites are at fixed locations, the antenna can be adjusted to the proper look angles and locked in position. However, the mounting structure should be designed so that minor adjustments (say \pm 10 degrees) in bot! azimuth and elevation can be made conveniently to compensate for installation inaccuracies. Because the inclination of the satellite will be held to about +0.1 degree, it should not ordinarily be necessary to reposition the antenna during normal. operations.

However, operation of the DCS may be changed from one satellite to another during eclipse periods, so that direct-readout users must reposition their antennas to another satellite to maintain continuity of operations. While the satellite is in eclipse, operational. restraints are placed on the satellite, because of limited power available. These eclipse periods occur for intervals up to 72 minutes a day each day for 6 weeks, twice a year.

If the antenua will be used with more than one satellite or family of satellites, it is recommended that repositioning of the antenna be done by remote control.

The S-band transmissions from the SMS/GOES satellites are linearly polarized. If the full capability of the receiving antenna is to be realized, the antenna must also be linearly polarized so that it is parallel to the polarization of the received signal. Because of different aspect angles to different satellites, the polarization of the signal cannot be predicted at the Earth's surface. For this reason, the polarization of the antenna should be adjustable. Where the antenna will be used with only one satellite, the 


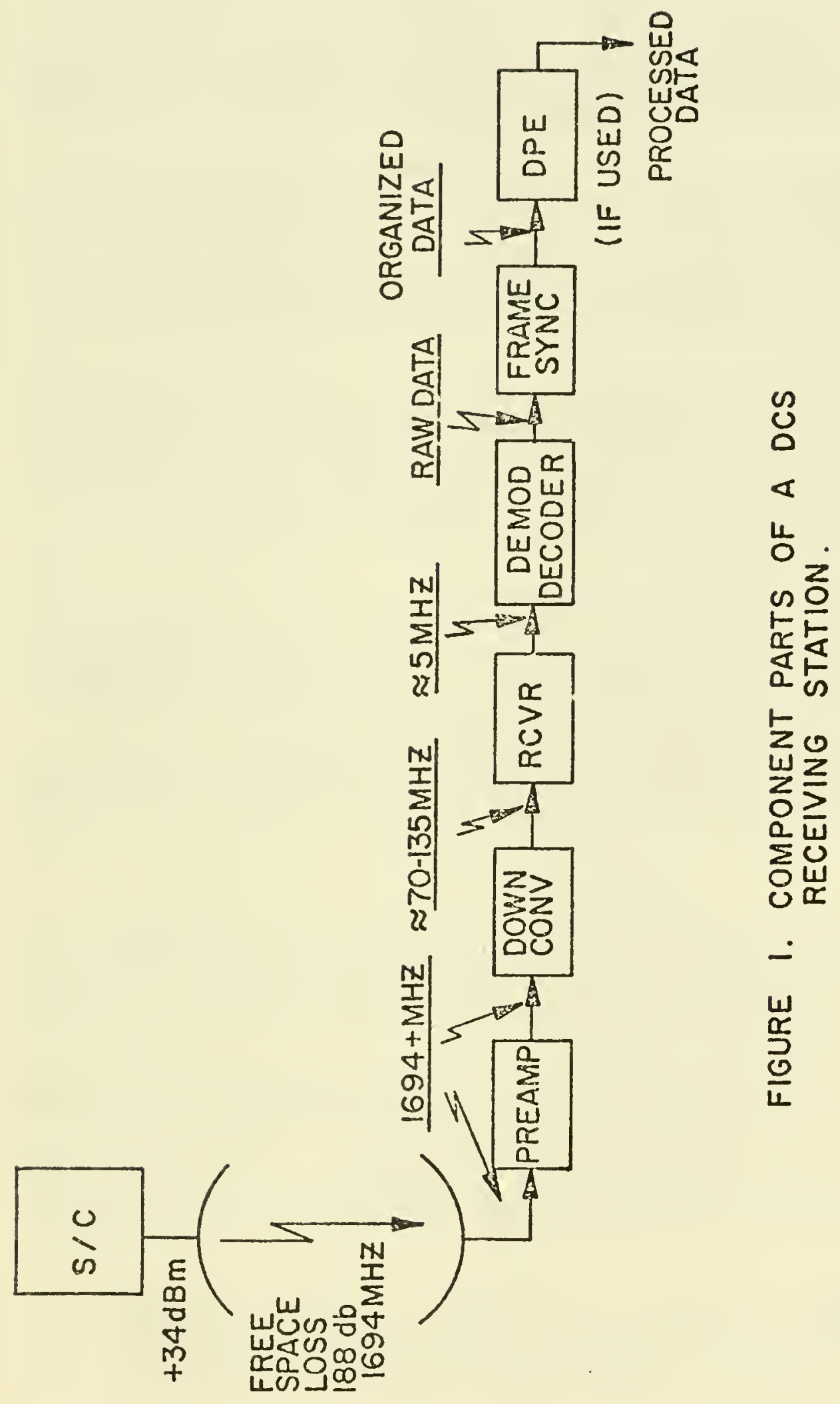


polarization angle can be adjusted for maximum received signal and locked in that position. If the antenna will be used with more than one satellite, it will be convenient to make the polarization as well as the antenna position remotely controlled.

\section{PREAMPLIFIER}

Considerable thought should be given to the preamplifier as it will play an important role in determining the error rate of the system and the size of the antenua.

Many types of amplifiers are discussed in detail in the material that follows. For purposes of this discussion, the important parameter is noise temperature, with a low noise temperature being more desirable.

To maximize performance of the system, it is standarci practice to mount the preamplifier on the antenna, making the corriection between the preamplifier and antenna as short as possible. For a similar reason, the downconverter is usually located as close to the preamplifier as practical. Several manufacturers supply a preamplifier and downconverter in one package for direct mounting at the antenna's terminals.

\section{DOWNCONVERTER}

The purpose of the downconverter is to translate the sateliite signal from the vicinity of $1694.5 \mathrm{MHz}$ down to a more convenient frequency. If the user is independently assembling a station using a surplus VHF WEFAX or APT receiver ${ }^{2}$, the downconverter output frequency is usually in the vicinity of $137 \mathrm{MHz}$. Where the user is buying a complete package receiver, this frequency may be in the neighborhood of $70 \mathrm{MHz}$. Other conversion frequencies are also used.

\section{RECEIVING SYSTEM}

Although all the components discussed above can be considered part of the receiving system, the term "receiver" is generally reserved for that part of the receiving system that contains the power supplies and control circuits and provides most of the amplification. Special units may be acquired or available equipment adapted for this application.

In addition to the usual functions provided by the receiving system, it is desirable that the receiver lock onto and track a pilot carrier. This carrier is transmitted from the Wallops CDA station and is returned on a nominal frequency of $1694.450 \mathrm{MIz}$. The receiver should track the deviation from this pilot carrier frequency ( $\pm 20 \mathrm{kHz}$ ) to compensate for drift in the satellite translation frequency and control internal receiver drift as well.

2/ Nagle, John J., "A Method of Converting the SMS/GOES WEFAX Frequency ( $1691 \mathrm{MHz}$ ) to the Existing APT/WEFAX Frequency (137 MHz)." Technical Memorandum NESS 54, NOAA/NESS Office of System Engineering, April, 1974. 
The input to the receiver must be compatible with the output of the downconverter, and the receiver output must be compatible with the input requirements of the demodulator.

\section{DEMODULATOR/DECODER}

The output of the receiver is fed to a separate demodulator/decoder external to the receiver at a convenient intermediate frequency (IF). The demodulator portion converts this IF signal to a series of d.c. pulses. The decoder portion separates the clock and the data stream to recover the information.

If the user purchases a sperial receiver for DCS reception, the demodulator/decoder may be luilt into the receiver. In either case, the demodulator/decoder wili recover the data from the phase shift signal. In principle, the output of the decoder should be the same as the sensor data input to the radio set transmitter at the remote platform.

\section{FRAME SYNCHRONIZER}

Following the decoder, a frame synchronizer must be provided to recognize the 15-bit Maximal Lengtb Sequence (MLS) synchronizing data pattern and ensure that the data bits are outputted in the proper sequence.

\section{DATA PROCESSING EQUIPMENT}

Where a large amount of data is to be received, or where the data must be processed, automatic processing equipment is necessary. The design of this equipment depends on the requirements of the user and cannot be discussed in general.

\section{DCS SIGNAL POWER}

The energy available in the received signal plays an important role in determining the necessary quality and, hence, cost of the receiving system. Unfortunately, the received signal level can vary over a wide range; a lodB variation may be typical (a numerical variation of 10). There are various causes for this variation, all of which are beyond the control of the user. The most probable cause is satellite loading; i.e., the number of other platforms transmitting at the same time.

During emergency situations many more platforms may be programed to respond in their emergency mode than would normally be transmitting. Unfortunately, this tends to lower signal levels at a time when the data are most needed.

The power radiated by the satellite in the DCS band under normal conditions is 2.5 watts. This power is known as the equivalent isotropic radiated power (EIRP). This 2.5 watts is available to be shared equally by all channels. Thus, if everything were ideal and 
only one channel transmitting, the entire 2.5 watts would be available to this one channel. If two channels were transmitting simultaneously, the 2.5 watts would be shared equally between both channels. The power in each channel will be reduced by $3 \mathrm{~dB}$. (Note: A reduction of $3 \mathrm{~dB}$ is equivalent to a numerical factor of one-half). Although there are 183 possible channels, statistically it is very highly unlikely that all 183 will ever be transmitting simultaneously. A more reasonable number of channels transmitting simultaneously might be 100 , which will give a $20 \mathrm{~dB}$ per channel reduction in signal level from 2.5 watts. (Note: A $20 \mathrm{~dB}$ reduction corresponds to a numerical reduction of 100).

The situation is not ideal, however. The satellite uplink receiver puts out noise which is rebroadcast by the transmitter along with the desired signais. This rebroadcast noise requires transmitter energy that would otherwise be available for useful signals. The amount of energy converted into noise is equivalent to approximately 10 simultaneous signal channels. This amounts to a reduction of $10 \mathrm{~dB}$ in the useful, available power when a small number of channels are active. (Note: A reduction of lodB is equivalent to a numerical reduction of one-tenth). When a large number of channels are active, say 100 or more, this noise component tends to be suppressed. The available energy is then equally distributed among the active channels. The power reduction for 100 channels is only $20 \mathrm{~dB}$ instead of 30dB. (Note: $20 \mathrm{~dB}$ is equivalent to a numerical value of 100 while $30 \mathrm{~dB}$ is equivalent to 1000). This is discussed in more detail in Appendix A.

From the above, it can be seen that available power per channel can vary from about 0.25 watts when only one channel is active to about 0.25 watts when 100 channels are transmitting simultaneously. This is a lodB variation in the available received energy and can occur at random.

Another factor to be considered is that, beginning with the GOES-2 satellite, a low-power mode is used operationally. In this mode the total satellite transponder output power is 0.4 watis or a reduction of $8 \mathrm{~dB}$ from the 2.5-watt level. (Note: $8 \mathrm{~dB}$ is a numerical reduction by one-sixth). However, the DCS signal will actually be reduced by only about $2 \mathrm{~dB}$ ( 40 percent); this is because VISSR and S-VISSR are not transmitted in the low-power mode so, except for telemetry which is small, the entire transponder power is then available to the DCS. It is expected that the low-power mode will be used during the predictable eclipse periods.

The free-space loss between isotropic antennas from synchronous altitude to the subsatellite point is $188 \mathrm{~dB}$; the free-space loss to Earth's edge is increased to 189.3dB. The satellite transmitting antenna gain is $2 \mathrm{~dB}$ less at Farth's edge than at the subsatellite point. In addition, the radiation pattern of the satellites favors the Northern Hemisphere, so that there is an additional loss of about $2 \mathrm{~dB}$ at the Earth's edge in the Southern Hemisphere. The signal level that can be expected at Earth's edge in the Southern Hemisphere is, therefore, approximately 
$24 \mathrm{dBm}-(189 \cdot 3+2+2) \mathrm{dB}=-169 \cdot 3 \mathrm{dBm}$ and about $2 \mathrm{~dB}$ more in the Northern Hemisphere. (Note: In making signal level calculations it is convenient to express power levels in decibel form. Since a decibel represents a ratio of two power levels, it is necessary to specify a reference level when absolute power is specified in decibel form. By convention, one of two values is used as a reference. When a power level is specified in $\mathrm{dBm}$, the reference is understood to be 1 miliiwatt, $10^{-3}$ watts. When the power is expressed in $\mathrm{dBw}$, the reference is understood to be I watt. Thus, $+34 \mathrm{dBm}$ is a power level $34 \mathrm{~dB}$ above $10^{-3}$ watts or 2.5 watts. Similarly, $4 \mathrm{dBw}$ is a power $4 \mathrm{~dB}$ above 1 watt or 2.5 watts. A power level given in $\mathrm{dBw}$ may be converted to $\mathrm{dBm}$, or vice versa, by adding or subtracting $30 \mathrm{~dB}$ since the difference between 1 watt and $10^{-3}$ watts is $30 \mathrm{~dB}$ ).

The natural noise against which the signal energy must compete is composed of two components. The first is cosmic noise with an effective noise temperature of about 75 degrees Kelvin ( $K$ ) for an elevation angle of 5 degrees or more. This noise will be nearly constant with increases occurring only when the antenna beam sweeps past radio stars or the Sun. The user has no control over this source of noise.

The second major source of noise is the receiver. The noise contribution of the receiver is measured by its noise temperature; another term often used is noise figure. As the noise temperature of a receiver is difficult to measure directly, it is standard practice to measure the receiver noise figure and convert this to noise temperature. The noise temperature and noise figure are related by equation ( 1 ).

$$
\overline{\mathrm{NF}}=10 \log \left(\frac{\text { Trec }}{\text { Tref }}+1\right)
$$

where

$$
\begin{aligned}
& \overline{\mathrm{NF}}= \\
\text { Trec }= & \text { receiver noise temperature (degrees Kelvin) } \\
\text { Tref = } & \begin{aligned}
& \text { reference temperature (degrees Kelvin see } \\
& \text { discussion below) }
\end{aligned} \\
\log = & \text { is the logarithm to the base } 10
\end{aligned}
$$

The reference temperature, Tref, is usually taken to be in the vicinity of ambient room temperature, approximately $293^{\circ} \mathrm{K}$. In the material that follows. a reference temperature of $289.855^{\circ} \mathrm{K}$ will be used. The reason for this choice is that when $289.855 \mathrm{~K}^{\mathrm{O}}$ is multiplied by Boltzmann's constant ( $1.38 \times 10^{-23}$ joules per ${ }^{{ }^{\circ}} \mathrm{K}$ ) 
the product is a round number $\left(4 \times 10^{-21}\right)$ that is convenient to manipulate in both algebraic and logarithmic form $\left(10 \log 4 \times 10^{-21}=\right.$ $-204 \mathrm{dBw}$ per Hertz bandwidth).

It is important to determine the reference temperature when comparing specifications from different manufacturers.

\section{ANTENNA/RECEIVER CONSIDERATIONS}

The noise temperature of a receiver is largely determined by the input stage of the receiver. Typical noise figures and noise temperatures of various commonly used input amplifiers in the 1. $7 \mathrm{GHz}$ frequency range are given below:

Typical bipolar transistor

Premium grade bipolar transistor

Gallium-Arsenide (GAS) FET

Noncooled (ambient temp.) parametric amplifier

Cryogenic parametric amplifier

$\begin{array}{lrl}\overline{N F} & \text { Noise } & \text { Temp. } \\ \mathrm{dB} & \mathrm{o}_{\mathrm{K}}\end{array}$

4

3

1.5

120

0.69

0.29

20

438

289

50
Approx. Cost

$\$$ 350.00

$\$ 600.00$

$\$ 1,500.00$

$\$ 25,000.00$

$\$ 100,000.00$

(Note: These numbers are approximate as they neglect the noise contribution of succeeding stages. This should be small if the gain of the input amplifier is large, say lodB or more.

As an example, if a premium grade biopolar transistor amplifier with a noise temperature of $289^{\circ} \mathrm{K}$ is used, to which must be added the antenna noise temperature of $750 \mathrm{~K}$, the result is a total system noise temperature of approximately $364^{\circ} \mathrm{K}$. The noise power in a $1-\mathrm{Hz}$ bandwidth is given by:

$$
\begin{aligned}
\text { Noise power }= & \left.1.38 \times 10^{-23} \text { (joules per }{ }^{\circ} \mathrm{K}\right) \times \\
& 365^{\circ} \mathrm{K}=5.02 \times 10^{-21} \text { watts } / \mathrm{Hz} \\
= & -203 \mathrm{dBw} / \mathrm{Hz} \\
= & -173 \mathrm{dBm} / \mathrm{Hz}
\end{aligned}
$$

As the DCS information is $100 \mathrm{bits} / \mathrm{s}$, the postdetection bandwidth must be $100 \mathrm{~Hz}$. The noise power in a 100-Hz bandwidth will therefore be 100 times (or $20 \mathrm{~dB}$ ) greater than the noise power in a 1-Hz bandwidth. The total noise power at the receiver output will be $-153 \mathrm{dBm} / 100 \mathrm{~Hz}$. This is the natural noise against which the signal must compete. 
In addition to natural noise described above, there is a source of noise peculiar to the SMS/GOES family of satellites, called spin modulation or "spin mod."

The SMS/GOES satellites are spin stabilized, which means they must spin continuously to maintain correct attitude. The spin rate is nominally 100 revolutions per minute (rpm).

The antenna elements for the communications system are located around the periphery of the satellite. As the satellite spins, it is necessary to continuously switch the output of the transmitter to those elements that are facing the Earth. This is called an "electronically despun antenna."

As an antenna element on one side of the satellite is passing out of view of the Earth and is being switched off, an antenna element on the opposite side of the satellite is coming into the Earth's view and is being switched on. It can, therefore, be visualized that the electrical center of the antenna rotates around the satellite in a direction opposite to the rotation of the satellite. Therefore, the antenna pattern is always pointing toward the Earth.

The spin mod noise is peculiar to the electronically despun antennas that are used on the SMS-1 and 2 , and GOES-1, 2 , and 3 satellites. If the phase center of the antenna were located on the spin axis of the satellite, the problem would not exist. A more detailed descriptin of this source of noise is given in Appendix B.

At the time this report is being written, it is expected that the next generation of GOES satellites (GOES-D, E, and F) will use a mechanically despun antenna. With this type of antenna, the antenna mechanically spins in a direction opposite to the spin direction of the sateliite, so that the antenna appears stationary with respect to the Earth. As there will be no switching of antenna elements, the phase center of the antenna will remain constant and there will be no spin mod. This will improve the operation of the system by reducing the noise against which the desired signal uust compete. The spin-mod has been measured as $40^{\circ}$ peak-to-peak for Earth stations located on the same longitude as the satellite and $70^{\circ}$ peak-to-peak for Earth stations located on the horizon at the Equator.

Unfortunately, the desired signal information is also phase modulated on the carrier so that spin mod caused by the antenna switching appears as noise along with the desired information. This noise is in addition to the natural noise described previously.

It is therefore necessary to have a higher carrier-to-noise ratio (CNR) than would otherwise be required.

The CNR actually needed depends on the highest bit-error rate (BER) that is considered acceptable for the user. Considering 
only natural noise (excluding spin modulation noise), the BER for the DCS system is given by

$$
\operatorname{BER}=1 / 2 \mathrm{e}^{-0.794 \frac{\mathrm{C}}{\mathrm{N}}}
$$

where $C / N$ is the $C N R$ as a numeric (not in $d B$ ) and $e=2.71828$. This equation is derived from statistical communication theory. Because of the spin modulation noise, the required CNR will be somewhat higher than given by equation (2).

Direct measurements on GOES A, B, and C show that a CNR of $14 \mathrm{~dB}$ on the DCS over natural noise is necessary to give a BER of 1 in $10^{-5}$. This CNR is greater than predicted by equation (2), because it takes into account the spin modulation noise which equation (2) does not consider. As mentioned earlier, it is expected that the GOES-D, E, and F generation of satellites will not have spin modulation noise. Lower CNR's, which are more in agreement with equation (2), should be usable with these satellites.

The user should bear in mind that a CNR of $14 \mathrm{~dB}$ is necessary for a BER of 1 in $10^{5}$. If the user requires more accurate data (higher $B E R$ ), then 2 higher $C N R$ is necessary. This in turn will require a larger and more expensive antenna and/or lower noise preamplifier.

Conversely, if a lower error rate is acceptable, a lower CNR is permissible, resulting in a more economical receiving system. Users should, therefore, carefully analyze their BER requirements to ensure that they obtain adequate accuracy at the lowest cost.

As stated previously, the noise power at the receiver output will be $-153 \mathrm{dBm} / 100 \mathrm{~Hz}$ and that a CNR of $14 \mathrm{~dB}$ is necessary for a BER of 1 in $10^{5}$. Hence, a carrier level of $-153 \mathrm{dBm}+14 \mathrm{~dB}=-139 \mathrm{dBm}$ is required. As a signal level of only $-169.3 \mathrm{dBm}$ can be expected the difference, $-139 \mathrm{dBm}-(-169.3 \mathrm{dBm})=30.3 \mathrm{~dB}$, must be made up by using an antenna with $30.3 \mathrm{~dB}$. This requires a paraboloidal antenna with a diameter of 2.5 meters and assumes an aperture efficjency of 55 percent, which is typical for antennas of this type.

If the DCS system is heavily loaded ( 100 channels transmitting), the received signal per channel will be lodB lower and an antenna diameter of 3.16 times 2.5 meters $=7.9$ meters will be necessary. (Note: The gain of a paraboloidal antenna is directly proportional to its area. Therefore, the antenna gain is proportional to the square of the diameter. Increasing the antenna djameter by $\sqrt{10}=3.16$ will increase its area and hence its gain by a numerical factor of 10. This is equivalent to a lodB increase.)

If an uncooled parametric amplifier is used instead of a premium grade transistor amplifier, the receiver and antenna noise temperaturcs are now $50^{\circ} \mathrm{K}+75^{\circ} \mathrm{K}$ jespective] $=125^{\circ} \mathrm{K}$. The noise power in a $100-\mathrm{Hz}$ bandwidth is now $-157.6 \mathrm{dBm}$ instead of $-153 \mathrm{dBm}$. This represents an improvement of $4.6 \mathrm{dl} 3$ and a reduction in antenna 
size by the same amount $(4.6 \mathrm{~dB}$ and a reduction in antenna area by the same amount $(4.6 \mathrm{~dB}=$ a reduction of 1.7 in antenna diameter $)$. Hence, for the single channel case, the required diameter becomes 2.5 meters $/ 1.7=1.47$ meters and for the 100-channel loading case, 4.6 meters.

These values can be used as points on two curves, one curve for a single channel loaded DCS, and the other for a fully loaded system. Points for the other types of preamplifiers can be plotted, and a smooth curve drawn between them.

Figure 2 shows a family of curves giving the required antenna diameter as a function of system noise temperature for various numbers of simultaneous active channels. In using these curves the following conditions should be noted.

1. The abscissa (noise temperature) is the overall receiving system noise temperature and is the sum of the preamplifier noise temperature and the $75^{\circ} \mathrm{K}$ cosmic noise. The ordinate gives the required antenna gain.

2. A $3 \mathrm{~dB}$ margin, as well as miscellaneous losses of $3 \mathrm{~dB}$, are included.

3. All calculations are based on the receiver being located at the subsatellite point.

For convenience, Tables 1 and 2 give the margin obtained with some typical preamplifiers and antenna sizes of 3 and 10 meters. A wide variation in the available margin is evident.

All users must bear in mind that the National Environmental Satellite Service (NESS) cannot guarantee that usage of the DCS wi:II be limited to any maximum number of platforms, and therefore cannot guarantee a minimum signal level at the Earth's surface. Users must, therefore, carefully consider the consequences of lost or inaccurate data against the costs of building a better ground station.

\section{DEMODULATOR/DECODER}

To recover the data, the output of the receiver must be demodulated and decoded. A separate demodulator/decoder should be used for each DCS channel in use, although a single antenna-receiver combination can be used to drive a number of them.

It is recommended that the demodulator/decoder be purchased from a manufacturer experienced with the GOES DCS. Four problem areas must be considered; these are:

1. The Spin/Phase Noise: As described earlier, the spacecraft rotation causes spin modulation which appears as noise at 


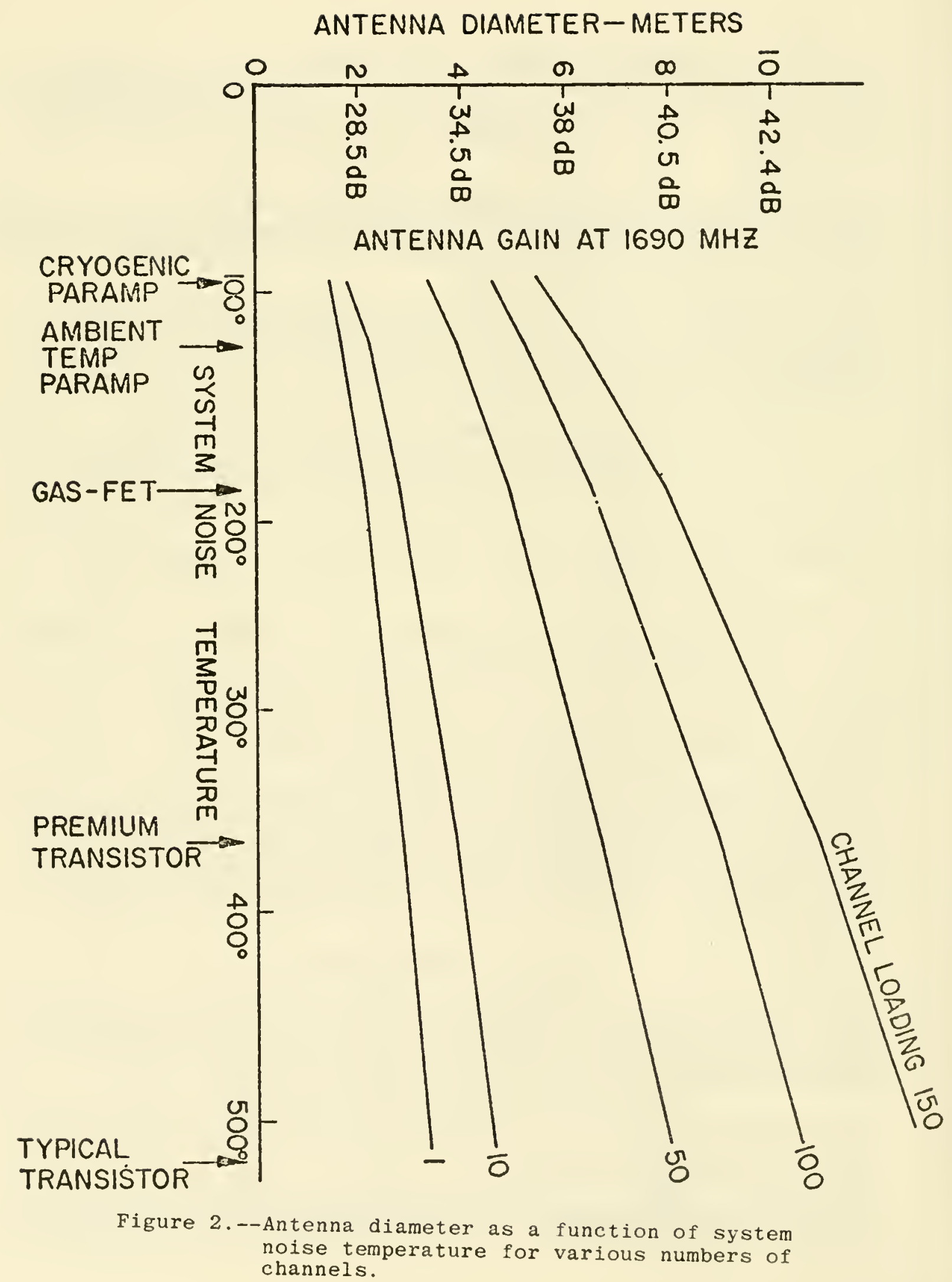


Table 1.--Typical Gain Margins Using a 2-Meter Antenna

\begin{tabular}{|c|c|c|c|c|c|c|c|c|}
\hline \multirow[b]{2}{*}{$\begin{array}{l}\text { Number of Simultaneous } \\
\text { Active Channels }\end{array}$} & \multicolumn{4}{|c|}{$\begin{array}{l}\text { Premiun Grade Transistor Preamp } \\
\mathrm{T}_{\text {rcur }}+\mathrm{T}_{\text {sky }}=364 \mathrm{O}_{\mathrm{K}}(=25.6 \mathrm{~dB}-\mathrm{K})\end{array}$} & \multicolumn{4}{|c|}{$\begin{array}{l}\text { Call ium-Arsenide FET } \\
T_{\text {rcvr }}{ }^{+T_{\text {sky }}}=195^{\circ} \mathrm{K}\left(=22.9 \mathrm{~dB}^{\circ} \mathrm{O}_{\mathrm{K}}\right)\end{array}$} \\
\hline & 1 & 10 & 50 & 100 & 2 & 10 & 50 & 200 \\
\hline EISP dBm & +34 & +34 & +34 & +34 & 34 & 34 & 34 & 1. 34 \\
\hline $\begin{array}{l}\text { Share loss } \\
+ \text { Noise Power dB }\end{array}$ & -10.4 & -13 & -17.8 & -20.4 & -10.4 & -13 & -17.8 & -20.4 \\
\hline Free Space Loss dB & -188 & -188 & -188 & -288 & -188 & -188 & -188 & -188 \\
\hline $\begin{array}{l}\text { Receiver Antenna Cain } \\
\text { dB }\left(55_{\%}^{\sigma}\right)\end{array}$ & +32 & +32 & +32 & +32 & 32 & 32 & 32 & 32 \\
\hline (Antenna Dlameter-Meters) & (3) & (3) & (3) & (3) & (3) & (3) & (3) & (3) \\
\hline $\begin{array}{l}\text { Pox Input Power Level } \\
\text { dBm }\end{array}$ & -132.4 & -135 & -139.8 & -142.4 & -132.4 & -135 & -139.8 & -142.4 \\
\hline $\begin{array}{l}\text { System Noise Temp. } \\
\text { dB-OK }\end{array}$ & .25 .6 & 25.6 & 25.6 & 25.6 & 22.9 & 22.9 & 22.9 & 22.9 \\
\hline $\begin{array}{l}\text { Boltzmans Constant } \\
\left(\mathrm{APm} / \mathrm{Hz}-\mathrm{O}_{\mathrm{K}}\right)\end{array}$ & -198.6 & -198.6 & -198.6 & -198.6 & -198.6 & -198.6 & -198.6 & -198.6 \\
\hline $\begin{array}{l}\text { Ixx Input Noise } \\
\mathrm{N}_{\mathrm{O}} \mathrm{d} \mathrm{m} / \mathrm{Hz}\end{array}$ & -173 & -173 & -173 & -173 & -175.8 & -175 & -175 & -175 \\
\hline $\begin{array}{l}\text { Px Input } \\
\mathrm{C} / \mathrm{N}_{\mathrm{O}} \mathrm{dB} / \mathrm{Hz}\end{array}$ & 40.6 & 38.0 & 33.2 & 30.6 & 43.4 & 40.8 & 35.9 & 33.3 \\
\hline Required $C / N_{0}(a b-12)$ & 31 & 34 & 34 & 34 & 3 & 34 & 34 & 34 \\
\hline $\begin{array}{l}\text { Miscellaneous Losses } \\
\quad \mathrm{dB}\end{array}$ & 3 & 3 & 3 & 3 & 3 & 3 & 3 & 3 \\
\hline Margin $(d B)$ & 3.6 & 1.0 & -3.8 & -6.4 & 6.4 & 3.8 & -1.1 & -3.7 \\
\hline
\end{tabular}

* Field Effect Transistor. 


\begin{tabular}{|c|c|c|c|c|c|c|c|c|}
\hline \multirow[b]{2}{*}{$\begin{array}{l}\text { Number of Simultaneous } \\
\text { Active Channels }\end{array}$} & \multicolumn{4}{|c|}{$\begin{array}{l}\text { Premium Grade Transistor Preant } \\
\mathrm{T}_{\mathrm{rcvr}}+\mathrm{T}_{\mathrm{sky}}=364 \mathrm{~K}_{\mathrm{K}}\left(=25.6 \mathrm{~dB}-\mathrm{O}_{\mathrm{K}}\right)\end{array}$} & \multicolumn{4}{|c|}{$\begin{array}{l}\text { Gallium-Arsenide FET Preamp. } \\
\mathrm{T}_{\text {recr }}+\mathrm{T}_{\text {sky }}=195^{\circ} \mathrm{K}\left(=22.9 \mathrm{~dB}-{ }^{\circ} \mathrm{K}\right)\end{array}$} \\
\hline & 1 & 10 & 50 & 100 & 1 & 10 & 50 & 100 \\
\hline EIPP dBn & +34 & +24 & +34 & +34 & 34 & 34 & 34 & 34 \\
\hline $\begin{array}{l}\text { Share Loss } \\
+ \text { Nolse Power dB }\end{array}$ & -10.4 & -13 & -17.8 & -20.4 & -10.4 & -13 & -17.8 & -20.4 \\
\hline Free Space Loss dB & -188 & -188 & -188 & -188 & -188 & -188 & -188 & -188 \\
\hline $\begin{array}{l}\text { Recelver Antenna Cain } \\
\mathrm{db}(55 \%)\end{array}$ & 42.5 & 42.5 & 42.5 & 42.5 & 42.5 & 42.5 & 42.5 & 42.5 \\
\hline (Antenna D1smeter-Meters) & (10) & (10) &.$(10)$ & (10) & (10) & (10) & (10) & (10) \\
\hline $\begin{array}{l}\text { Fox Input Ponver Level } \\
\text { dim }\end{array}$ & -121.9 & -224.5 & -129.3 & -131.9 & -121.9 & -124.5 & -129.3 & -132.0 \\
\hline $\begin{array}{l}\text { System Noise Temp. } \\
\text { dB_OK }\end{array}$ & 25.6 & 25.6 & 25.6 & 25.6 & 22.9 & 22.9 & 22.9 & 22.9 \\
\hline $\begin{array}{l}\text { Boltzmans Constant } \\
\text { (dBm/Hz - OK) }\end{array}$ & -198.6 & -198.6 & -198.6 & -198.6 & -198.6 & -198.6 & -198.6 & -198.6 \\
\hline $\begin{array}{l}\text { Pox Input Noise } \\
\mathrm{N}_{0} \mathrm{dBm} / \mathrm{llz}\end{array}$ & -173 & -173 & -173 & -173 & -175.7 & -175.7 & -175.7 & -175.7 \\
\hline $\begin{array}{l}\mathrm{Px} \text { Input } \\
\mathrm{C} / \mathbb{N}_{0} \mathrm{~dB} / \mathrm{Hz}\end{array}$ & 51.1 & 48.5 & 43.7 & 41.1 & 53.8 & 51.2 & 46.4 & 43.7 \\
\hline Required $\mathrm{C} / \mathrm{N}_{0}$ & 34 & 34 & 34 & 34 & 34 & 34 & 34 & 34 \\
\hline $\begin{array}{l}\text { Miscellaneous Losses } \\
\mathrm{dB}\end{array}$ & 3 & 3 & 3 & 3 & 3 & 3 & 3 & 3 \\
\hline Mangin $(d B)$ & 14.1 & 11.5 & 6.7 & 4.1 & 16.8 & 14.2 & 9.8 & 6.7 \\
\hline
\end{tabular}

* Field Effect Transistor. 
the demodulator output. Unfortunately, the switching rate of the electronically despun satellite antenna is fairly close to the data rate; therefore, the decoder must be able to differentiate between valid data and spin noise.

2. Manchester Coding: The DCS uses Manchester coding to transmit data through the system. This type of coding has the advantage that the clock rate is imbedded in the data stream and can be recovered from the data by the decoder. It is, therefore, not necessary to transmit the clock information separately or to impose extreme stability requirements on the oscillator at the remote platform.

Manchester coding may be described in terms of digital logic as the Exclusive OR function between the clock and data.

The Truth Table for the Exclusive OR function is given below:

TRUTH TABLE

EXCLUSIVE OR

\begin{tabular}{|c||ll|}
\multicolumn{1}{c|}{} & \multicolumn{1}{c}{ DATA } \\
\hline CLOCK & 0 & 1 \\
\hline 0 & 0 & 1 \\
\hline 1 & 1 & 0 \\
\hline
\end{tabular}

As can be seen, the output is zero if the clock and data are both one or zero, but is one if the clock and data are opposite. The advantage of this may be seen in the timing diagram (Figure 3 ). Regardless of the input data, the Manchester-encoded data will change state once and only once during each input data bit. These changes may be used to synchronize the decoder clock. In this manner the remote platform clock information will be carried along with the data.

3. Pattern Sensitivity: As stated above, the data collection platforms use a Manchester Code to transmit data. The decoder must be capable of extracting the clock rate from the data in the presence of the spin noise described above. Furthermore, it must be able to do this with any possible data bit pattern. The GOES DCS has standardized on the use of ASCII code with odd parity. The decoder, therefore, must be able to accommodate data having as few as two "bit transitions" per 8-bit character. Otherwise, loss of synchronization will permit errors to be received until the decoder resynchronizes. Unfortunately, consecutive zeros can represent valid data from some types of platforms. Some of the electronic techniques which can be used to minimize the spin modulation noise complicate the clock slip problem. 
$\mathrm{S}_{\mathrm{S}}^{0.01 \mathrm{tr}}$

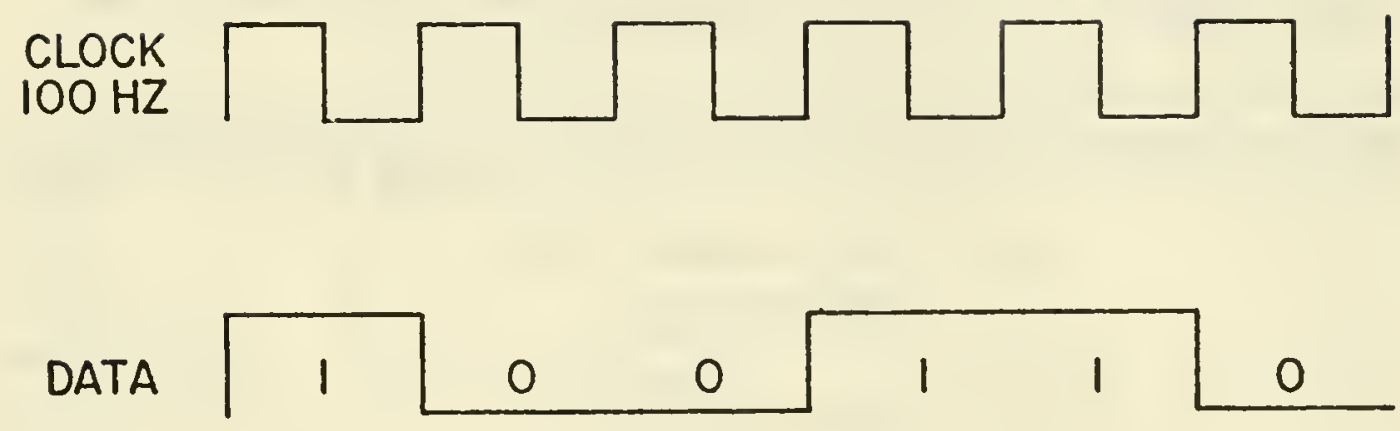

APPLY THE EXCLUSIVE OR TRUTH TABLE

AND OBTAIN

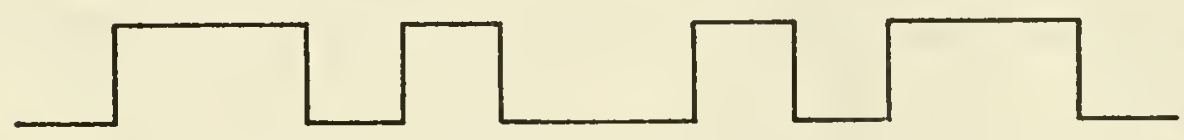

AS MANCHESTER-ENCODED

DATA

NOTICE THAT THE ENCODED DATA

CHANGES STATE ONCE DURING

EACH IPSPUT DATA BIT

FIGURE 3 
4. Interface: In addition to the above, the demodulator/decoder must properly interface with the receiver which immediately precedes it and with the frame synchronizer equipment which it feeds.

\section{FRAME SYNCIRONIZER}

After the signal has been decoded and the 100-Hz clock in the decoder "locked up" by the 2.5-second alternating 1-0 pattern, the decoder is ready to present data to the outside world. The next segment of the reply format is a 15-bit Maximal Length Sequence (MLS) pattern. The 15-bit MLS is recognized by a device called a "frame synchronizer" which must wait for decoder lock before looking for the 15-bit MLS. At the conclusion of the MLS, the frame syichronizer must be ready to present the received data in 8 -bit segments to the data processing equipment.

\section{DATA PROCESSING EQUIPMENT}

It is not possible to recommend a specific system for processing the received data, as this depends on the requirements of the user and on how the remote sensor outputs its data to the radio set. The cost of data processing system can be minimized by considering the processing, if any, that is done at the platform and user's data processing equipment. Obviously, the form of the data provided by the sensor and the computing system must be designed together if a cost effective system is to be developed. These depend on the user's specific requirements and can only be defined by the user. Generally, the data processing equipment must, as a minimum, include the following:
A. A proper interface to the frame synchronizer.
B. Interpretation of the 3I-bit DCP address.
C. Parity error checking.
D. Storage of the data.
E. A means of retrieving the data from storage.

\section{OBTAINING A DIRECT READOUT RECEIVING STATION}

The above material has briefly described system parameters; readers should bear in mind that NOAA/NESS cannot provide designs for particular users. Anycne considering establishing his own direct readout facility should contact vendors experienced in this area.

\section{IX. costs}

The following are rough estimates on costs of the various components: 
1. Antenna and Feed (Exc]uding Mounting Structure)

Diameter (meters)

1.2 (= 4 feet)

$1.8(=6$ feet $)$

2.4 (= 8 feet)

3.0 ( $=10$ feet $)$

3.6 (= 12 feet)

4.6 (= 15 feet)

9.1 (= 30 feet)

2. Preamplifier

Typical bipolar

transistor:

Premjum grade bipolar

transistor:

Gallium-arsenide FET:

Ambient temperature parametric amplifier:

Cryogenic parametric amplifier:

3. Receiver

4. Demodulator: (Includes channel filter)

5. Data processing equipment:
Cost (U.S. dollars)

500

800

1, 200

1, 750

3,600

8,950

25,000
350

600

1,500

25,000

100,000

3,000

4, 000

(Depends on application) 
Note: This report describes the equipment and operation requirements for the GOES/DCS in a general way.

Additional information about the DCS system and its use can be obtained by writing to:

\section{David S. Johnson, Director (S)}

National Environmental Satelite Service FOB \#4, ROOm 2069

Washington, D.C. 20233

Readers should bear in mind that the U.S. Government cannot comment on the relative merits of a particular design of a particular vendor. 

APPENDIX A

PER-CHANNEL SIGNAL ENERGY AS A FUNCTION OF THE NUMBER OF ACTIVE CHANNELS

The Equivalent Isotropic Radiated Power (EIRP) on a per-channel basis is given by

$$
\text { EIRP/Channel }=\frac{W \text { watts }}{X+N} \text { (in watts per channel) }
$$

where

$$
\begin{aligned}
W= & \text { the total EIRP available over the } \\
& 400-\mathrm{kHz} \text { DCS channel in watts (not } \\
& \text { in dBm). This is normally } 2.5 \text { watts, } \\
\mathrm{X}= & \text { the number of equal power users } \\
& \text { transmitting sinultaneously. The non- } \\
& \text { equal power users case will be discussed } \\
& \text { later, and } \\
\mathrm{N}= & \text { the noise-to-signal ratio at the input to } \\
& \text { the spacecraft receiver. }
\end{aligned}
$$

This ratio must be converted into a numerical form and not expressed in $\mathrm{dB}$. The noise power is calculated over the entire $400-\mathrm{kHz}$ DCS bandwidth and not over just the 100-Hz DCS data bandwidth. TypicaI numbers are: noise power over a 400-kHz bandwidth at the input to the spacecraft receiver $=-117 \mathrm{dBm}$ and the signal energy from a fixed platform is approximately $-127 \mathrm{dBm}$. Hence, the noise-tosignal ratio is nominally $10 \mathrm{~dB}$ which also happens to be a numerical ratio of 10 .

The EIRP as given by equation (1) will be given in watts which must be converted into an equivalent $\mathrm{dBm}$ number for most link calculations.

Applying the above to equation (1) gives, for typical cases,

$$
\operatorname{EIRP}=\frac{2.5}{\mathrm{X}+10} \text { watts/channel. }
$$

As can be seen from equation (2), when the number of channels transmitting simultaneously is small, say less than about five, the EIRP per channel is approximately constant at about 0.2 watts $(=23 \mathrm{dBm})$ per channel. When the number of channels transmitting simultaneously is large, greater than say about 20 , the EIRP will decrease linearly in watts as the number of channels transmitting increases. 
Equations ( 1 ) and (2) assume that all platforms are received at the same level by the spacecraft. Where the signal levels of the platforms as received at the spacecraft are not the same, as may be the case when fixed and buoy platforms are received simultaneously, the equation is slightly different. In this case equation (I) becomes

$$
\text { EIRP/ChanneI }=\frac{W \text { watts }}{\sum_{a}\left(X_{a}+N_{a}\right)} \quad \begin{gathered}
\text { watts per } \\
\text { channel })
\end{gathered}
$$

where

$$
\begin{aligned}
\mathrm{W}= & \text { EIRP in watts, as before } \\
\mathrm{x}_{\mathrm{a}}= & \begin{array}{l}
\text { number of channels received } \\
\text { simultaneously at a given level, } \\
\text { and }
\end{array} \\
\mathrm{N}_{\mathrm{a}=} & \text { noise-to-signal ratio (expressed } \\
& \text { as numeric) of those channels. }
\end{aligned}
$$

The summation is taken over all the different power levels and their respective noise-to-signal levels.

Equation (2) or (3) can also be used when the satellite is transmitting in low-power mode, as it will be during eclipse periods beginning with GOES-2 satellite. In this case, the numerator is 0.4 watts $(+26 \mathrm{dBm})$ instead of 2.5 watts. 


\section{APPENDIX B}

\section{CALCULATION OF THE PHASE MODULATION INTRODUCED BY THE SWITCHED ARRAY ANTENNA*}

The UHF antenna used for SMS is switched array. As the satellite spins, the transmitter and receiver are disconnected from one set of antenna elements and connected to another set (one element for transmit and one for receive). Since the radiating elements are in separate locations about the satellite periphery, the propagation path length from antenna to Earth terminal suddenly changes when the elements are switched. This effect causes a jump in RF carrier phase.

Also, because the phase center of the UHF satellite antenna is located off the axis of spin rotation, the propagation path length to the Earth terminal varies as the satellite rotates. This path variation introduces a phase (frequency) modulation on the transmitted and received carriers which may degrade link performance.

Figure B-1, shows the basic geometry, and Figure B-2 shows the phase shift as a function of time. The step in phase occurs when a new antenna is switched. The fundamental frequency of lhis phase modulation is eight times the spin rate (13.3Hz at $100 \mathrm{rpm})$. The worst case occurs on the DCP interrogation and reporting links with the DCP on Earth edge at the equator (in the plane of spin motion).

From Figure $\mathrm{B}-1$,

$$
\begin{aligned}
\Delta L & =R-R \cos (\theta-\alpha) \\
& =R(1-\cos (\theta-\alpha) \\
& =2 R \sin ^{2} \frac{\theta-d}{2}
\end{aligned}
$$

where $R$ is the antenna radius, $\alpha$ is the angle from the vertical to the Earth turminal (in the equatorial plane); and $\theta$ is the position of the UHF antenna element relative to the vertical.

Also,

$$
\Delta \phi=\frac{\Delta L}{\lambda}\left(360^{\circ}\right)
$$

*Obtained from the Ford Aerospace and Communications Corp. 
for

$$
\begin{aligned}
& \alpha=-9.2^{\circ} \text { (Earth edge }+0.5^{\circ} \text { tolerance), } \\
& \theta=22.5^{\circ}, \text { and } \\
& \mathrm{R}=26 \mathrm{in} .
\end{aligned}
$$

Then ,

$$
B=\theta-\alpha=31.7^{\circ}
$$

and the phase shift is $47.7^{\circ}$ at $401.9 \mathrm{MHz}$ and $55.6^{\circ}$ at $468.8 \mathrm{MHz}$.

A new element is switched in at this point, changing 0 to $-22.5^{\circ}$ and $\beta$ to $-13.3^{\circ}$. The phase shift jumps to $8.6^{\circ}$ at $401.9 \mathrm{NHz}$ and $10.0^{\circ}$ at $468.8 \mathrm{Mllz}$. The step change in pliase due to switching is $39.1^{\circ}$ at $401.9 \mathrm{MHz}$ and $45.6^{\circ}$ at $468.8 \mathrm{MII}$. This phase step occurs once every 75 us for a spin rate of $100 \mathrm{rpm}$. Figure B-3

shows how the peak phase and phase jump varies with $\alpha$. 


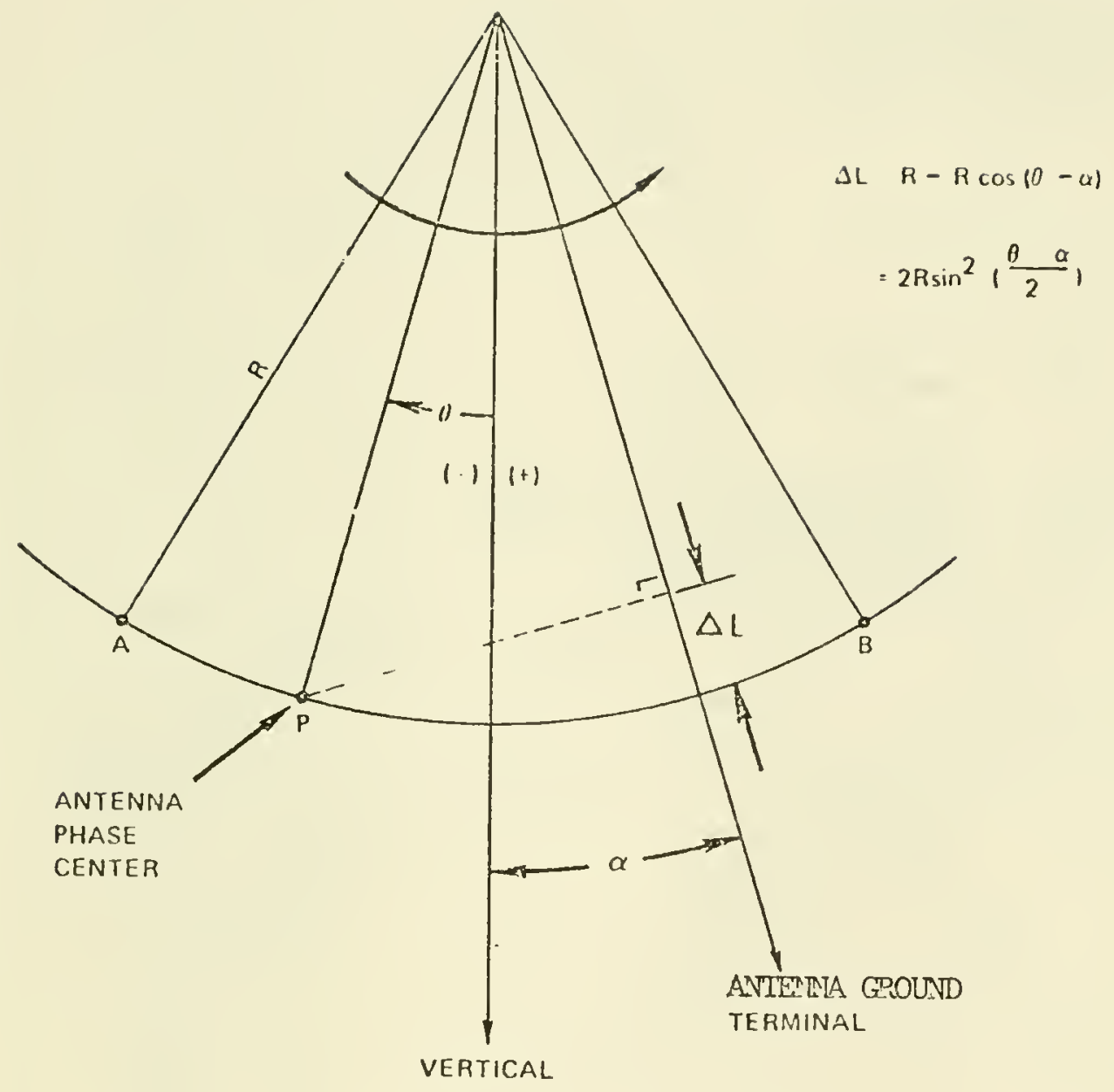

WHEN ANTENNA PHASE

CENTER ROTATES TO

B. THE ARRAY IS SWITCHED

AND THE PHASE: CENTER

JUMPS TO A. THIS CAUSES

A JUMP IN PHASE OF THE

RF CARRIER.

Figure B1.-- Geometry of Propagation Path Length to ground Variation liesulting frem Satcllite Spin Alotion 
FREQUENCY: $\quad 468.8 \mathrm{MHz}$

(401.9 $\mathrm{MHz}$ )

EARTH TERMINAL LOCATED ON EOUATOR

AT EARTH EDGE $\left(\alpha=9.1^{\circ}\right)$

ANTENNA RADIUS: 26 INCHES -

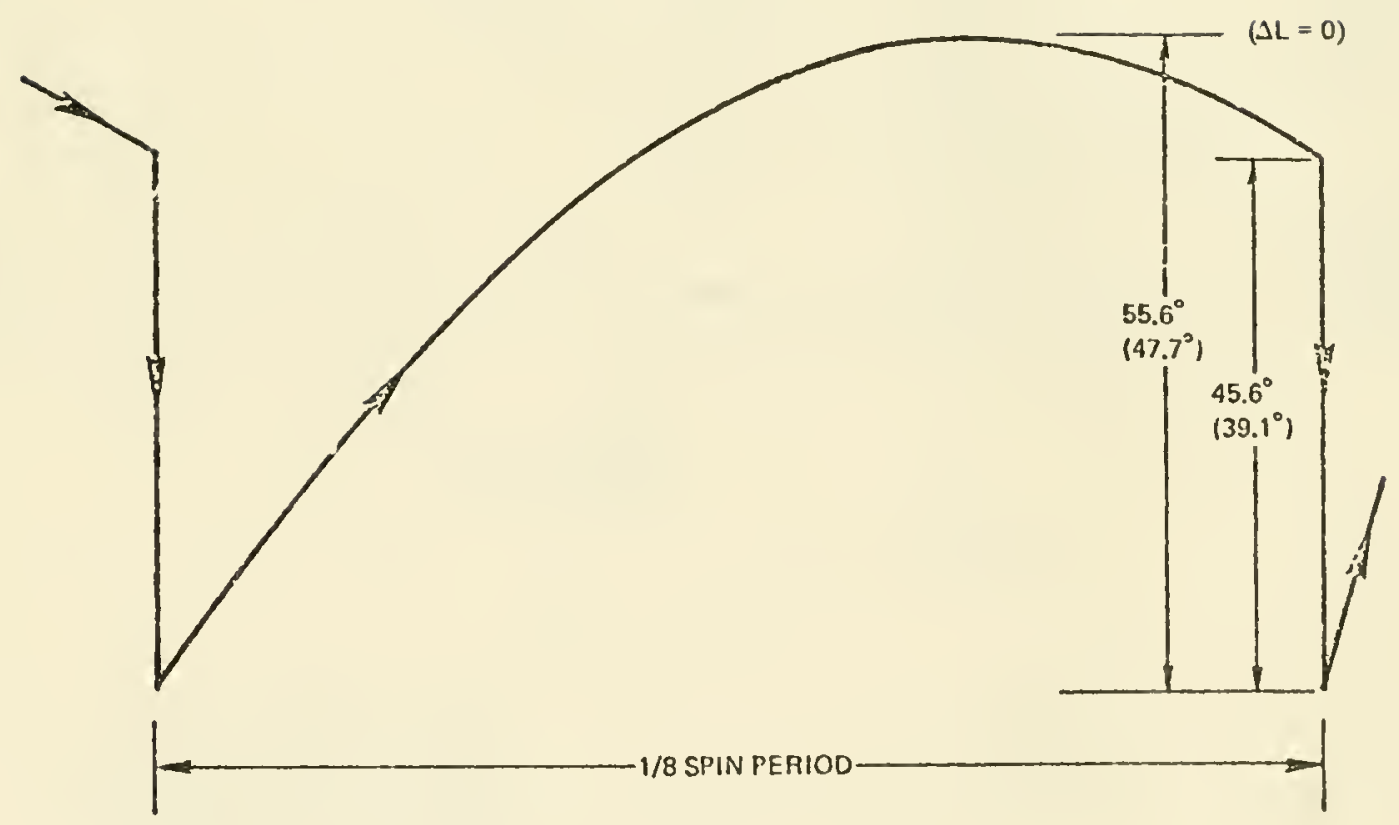

Pigure 32. - Phase Shift Introduced by Sitcllite Spin Motion and Element Switching in UIIF Antema. 


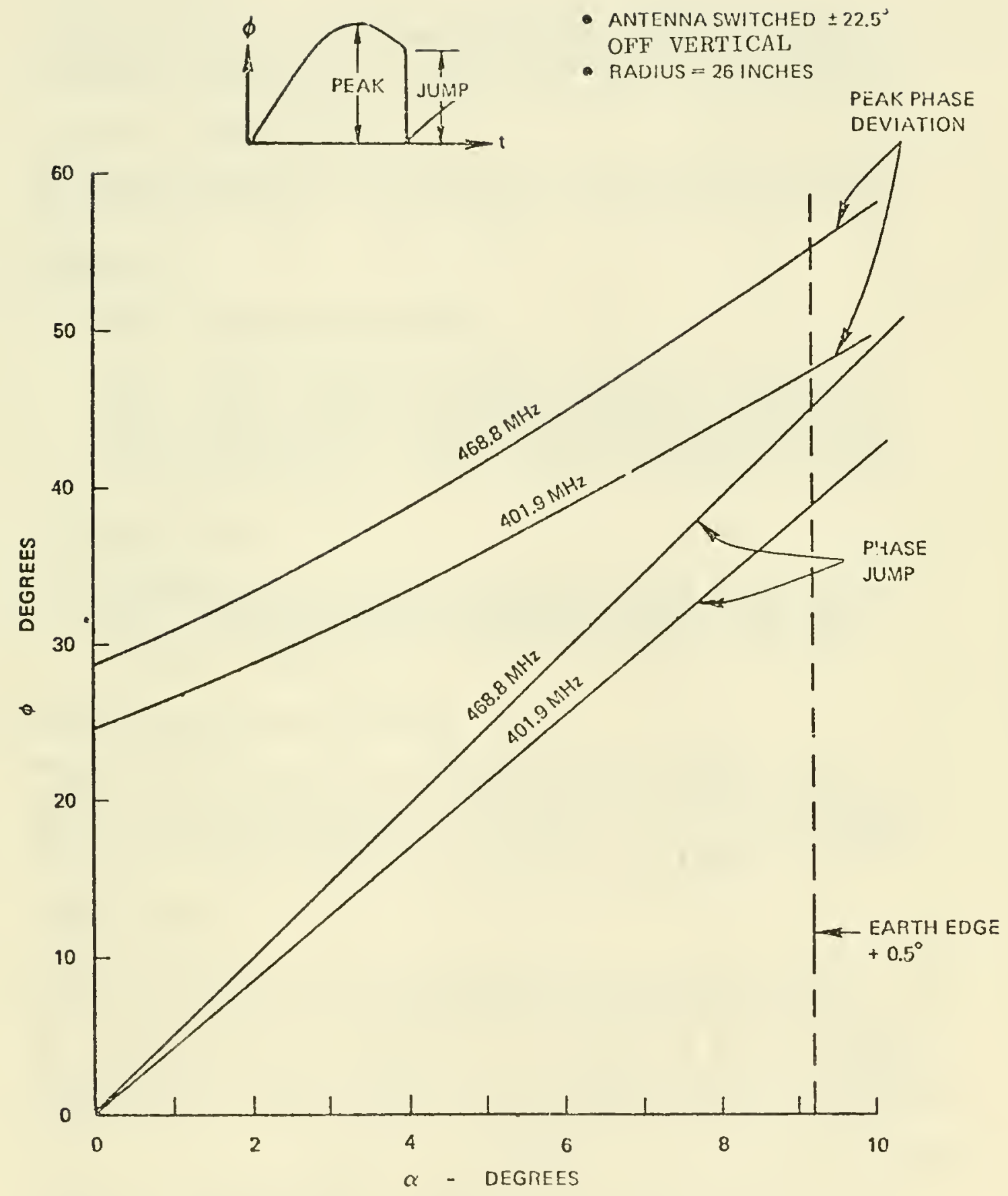

Figure 33.--Plase Modulation Caused by UIIF Satcllite Antenma Due to Spin Motion. 



\section{APPENDIX E \\ Certification Specifications for \\ International DCPRS}

1. RF Power Output

The Effective Isotropic Radiated Power (EIRP) of a DCPRS and antenna shall not exceed $52 \mathrm{dBm}$ under any combination of service conditions.

2. Frequency Characteristics

The DCPRS transmitted RF shall be in the $402.002577-\mathrm{MHz}$ to 402.098582-MHz band. (See Table 1.)

3. Stability

A. Temperature and Long Term

The transmitted carrier frequency stability shall be better than 1.5 parts per million against temperature variations and aging altogether. This specification applies typically over the temperature range of $-20^{\circ} \mathrm{C}$ to $+50^{\circ} \mathrm{C}$ and over 1 year, unless specified differently by the DCP operator.

B. Short Term

The phase jitter on the transmit carrier shall be less than $3^{\circ}$ RMS when measured through a phase lock loop two-sided noise bandwidth (2BL) of $20 \mathrm{~Hz}$ and within $\pm 2 \mathrm{KHz}$. (See Fig. 1.)

4. Electromagnetic Interference

Any transmitter spurious emissions, when measured with modulation and with antenna and diplexer connected, shall be down from the unmodulated carrier level by $60 \mathrm{~dB}$, (referred to a measurement bandwidth of $500 \mathrm{~Hz}$ ). International shipboard EMI specification should also be included.

5. Transmit Data

After 5 seconds of unmodulated carrier, the carrier shall be modulated with the bit and message synchronization data patterns which are 2.5 seconds of alternate 1,0 data bits, and the 46-bit preamble consisting of the 15-bit MLS synch word (100010011010111) followed by the 31-bit BCH address word (different for each platform), and a message proper consisting of 8-bit data words. The binary data shall be Manchester encoded and shall modulate the carrier in the following manner:

A data " 0 " shall consist of $+60^{\circ}$ carrier phase shift for 5 milliseconds followed by $-60^{\circ}$ carrier phase shift for 5 milliseconds, and a data "l" shall consist of $-60^{\circ}$ carrier phase shift for 5 milliseconds followed by $+60^{\circ}$ carrier phase shift for 5 milliseconds. (See Fig. 2.) The phase of the 5 seconds unmodulated carrier shall correspond to the phase of the modulated carrier. 
6. End of Transmission

Immediately after sending the sensor data, the DCPRS shall transmit 3l-bit End-of-Transmission (EOT) code (bit pattern 0010000010111010100111100011 ) continuously with the sensor data (no break) and return to the standby mode.

The first 8 bits of the 31 -bit EOT shall be the International Alphabet No. 5, 8 bits EOT (ODD parity Po):

First transmitted bit - 0010000010111011010100111100011 last transmitted

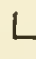
bit

IA. No. 5 EOT

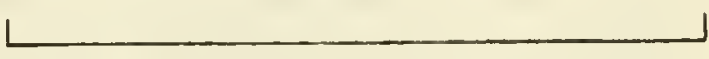

31 bits PRN sequence

7. Fail-Safe Design

The DCPRS shall incorporate a fail-safe design feature such that malfunctioning of the equipment shall in no way cause discontinuous transmission. Furthermore, provision shall be made to automatically terminate the transmission at a time not to exceed the platform's allocated transmission plus 30 seconds.

8. Antenna Polarization

Polarization shall be right-hand circular according to CCIR Report No. 321 (XIIIth Plenary Assembly, 1974 - Vol. XII).

9. Timing Accuracy

The timer that determines the DCPRS reporting time shall be of sufficient accuracy to ensure that the DCFRS reporting time is maintained to within 30 seconds of its assigned reporting time. The timer shall provide for a reporting interval of 1 to 12 hours in 1 -hour steps. Furthermore, the timer shall be capable of being set in steps of 60 seconds.

10. Clock Output

The DCPRS shall provide a $100 \mathrm{~Hz}$ clock frequency. This frequency shall be used to clock in the reply data. The l00-Hz clock frequency shall have a long-term temperature stability better than 50 parts per million.

11. Data Input

The DCPRS shall accept, from an interface unit with environmental sensors or manual data input device, a serial bit flow NRZ-L, $100 \mathrm{bits} / \mathrm{s}$ coded in International Alphabet No. 5. (See Fig. 3.) 


\section{Start Signal}

The DCPRS shall provide a start signal at the required time of transmission. This start signal generated from the timer will initiate the read-out of data from the interface unit. 
TABLE 1

FREQUENCY ALLOCATION FOR INTERNATIONAL

DCP RESPONSE CHANNEL

No. of

Channel

1

2

3

4

5

6

7

8

9

10

11

12

13

14

15

16

17

18

19

20

21

22

23

24

25

26

27

28
Frequency

$\mathrm{MHz}$

Remarks

402.002577

402.005577

402.008577

402.011577

402.014577

402.017578

402.020578

402.023578

402.026578

402.029578

402.032578

402.035579

402.038579

402.041579

402.044579

402.047579

402.050579

402.053579

402.056580

402.059580

402.062580

402.065580

402.068580

402.071580

402.074581

402.077581

402.080581

402.083581 
No. of

Channel

29

30

31

32

33

\section{Frequency}

$\mathrm{MHz}$

Remarks

402.086581

402.089581

402.092581

402.095582

402.098582 


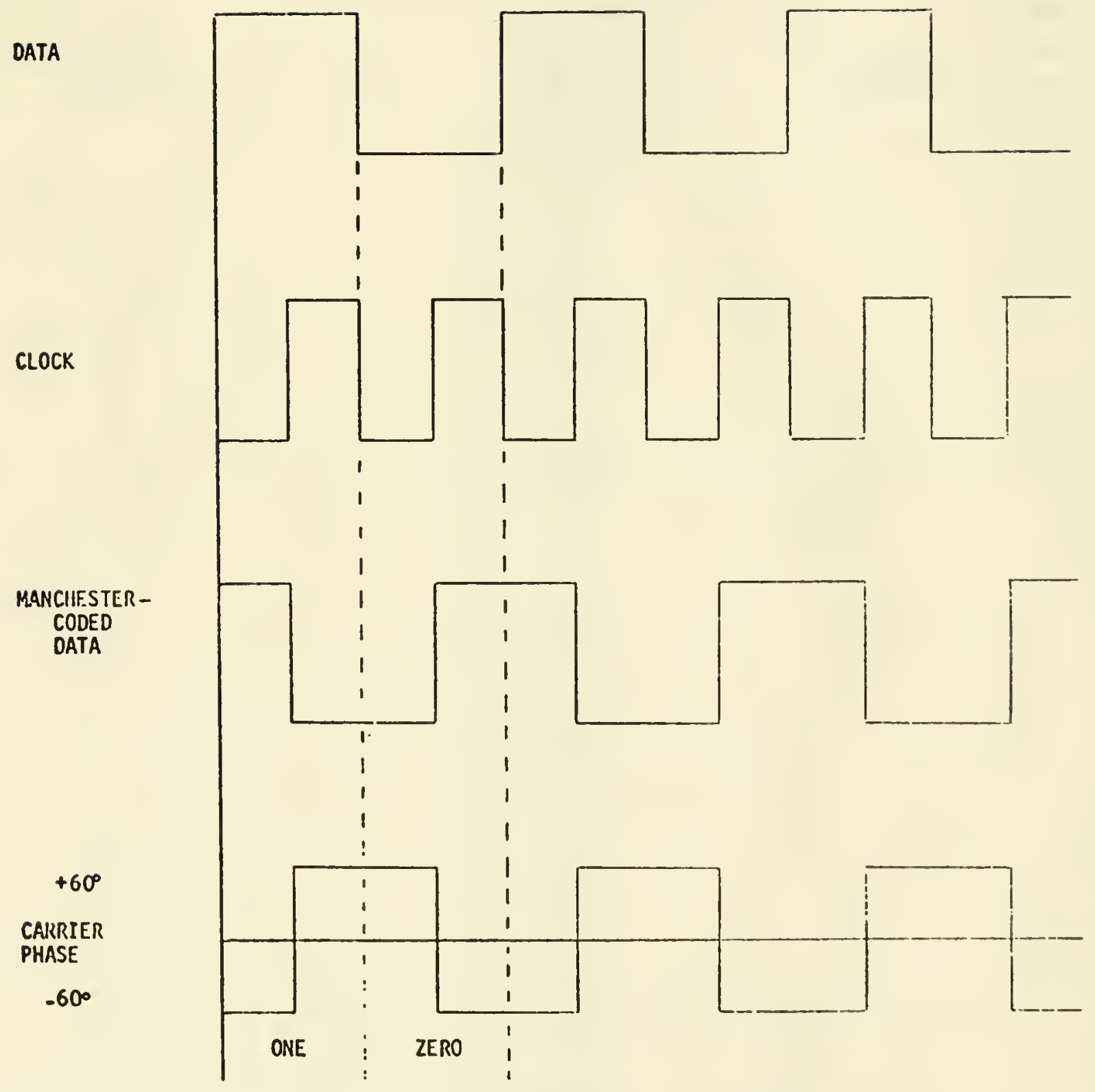

Figure 1.--Modulation Definition. 
NESS 55 The Use of Satellite-Observed Cloud Patterns in Northern Hemisphere 500-mb Numerical Analysis. Roland E. Nagle and Christopher M. Hayden, Apri1 1971, 25 pp. plus appendixes A, B, and C. (COM-73-50262)

NESS 57 Table of Scattering Function of Infrared Radiation for Water Clouds. Giichi Yamamoto, Masayuki Tanaka, and Shoj1 Asano, Apr 11 1971, 8 pp. plus tables. (COM-71-50312)

NESS 58 The Alrborne ITPR Brassboard Experiment. W. L. Smith, D. T. Hilleary, E. C. Baldwin, W. Jacob, H. Jacobowltz, G. Nelson, S. Soules, and D. Q. Wark, March 1972, 74 pp. (COM-72-10557)

NESS 59 Temperature Sounding From Satelites. S. Fritz, D. Q. Wark, H. E. Fleming, W. L. Smith, H. Jacobowitz, D. T. Hilleary, and J. C. Allshouse, July 1972, 49 pp. (COM-72-50963)

NESS 60 Satellite Measurements of Aerosol Backscattered Radiation From the Nimbus F Earth Radiation Budget Experiment. H. Jacobowitz, W. L. Smith, and A. J. Drummond, August 1972, 9 pp. (COM-7251031)

NESS 61 The Measurement of Atmospheric Transmittance From Sun and Sky With an Infrared Vertical Sounder. W. L. Smith and H. B. Howe11, September 1972, 16 PP. (COM-73-50020)

NESS 62 Proposed Calibration Target for the Visible Channel of a Satellite Radiometer. K. L. Coulson and H. Jacobowttz, October 1972, 27 pp. (COM-73-10143)

NESS 63 Verification of Operational SIRS B Temperature Retrievals. Harold J. Brodrick and Christopher M. Hayden, December 1972,26 pp. (COM-73-50279)

NESS 64 Radiometric Techniques for Observing the Atmosphere From Aircraft. William L. Smith and Warren J. Jacob, January 1973,12 pp. (COM-73-50376)

NESS 65 Satellite Infrared Soundings From NOAA Spacecraft. L. M. McMillin, D. Q. Wark, J.M. Siomkajlo, P. G. Abel, A. Werbowetzki, L. A. Laurltson, J. A. Pritchard, D. S. Crosby, H. M. Woolf, R. C. Luebbe, M. P. Weinreb, H. E. Fleming, F. E. Bittner, and C. M. Hayden, September 1973,112 Pp. (COM-73-50936/6AS)

NESS 66 Effects of Aerosols on the Determination of the Temperature of the Earth's Surface From Radiance Measurements at $11.2 \mathrm{~m}$. H. Jacobowitz and K. L. Coulson, September 1973, 18 pp. (COM-7450013)

NESS 67 Vertical Resolution of Temperature Profiles for High Resolution Infrared Radiation Sounder (HIRS). Y. M. Chen, H. M. Woolf, and W. L. Smith, January 1974, 14 pp. (COM-74-50230)

NESS 68 Dependence of Antenna Temperature on the Polarlzation of Emitted Radiation for a Scanning Microwave Radiometer. Norman C. Grody, January 1974, 11 pp. (COM-74-50431/AS)

NESS 69 An Evaluation of May 1971 Satellite-Derived Sea Surface Temperatures for the Southern Hemisphere. P. Krishna Rao, Apri1 1974, 13 pp. (COM-74-50643/AS)

NESS 70 Compatibility of Low-Cloud Vectors and Rawlns for Synoptic Scale Analysis. L. F. Hubert and L. F. Whitney, Jr., October 1974, 26 pp. (COM-75-50065/AS)

NESS 71 An Intercomparison of Meteorological Parameters Derived From Radiosonde and Satellite Vertical Temperature Cross Sections. W. L. Smith and H. M. Woolf, November 1974, 13 pp. (COM-75-10432)

NESS 72 An Intercomparison of Radiosonde and Satelltte-Derived Cross Sectlons During the AMTEX. W. C. Shen, W. L. Smith, and H. M. Woolf, February 1975, 18 pp. (COM-75-10439/AS)

NESS 73 Evaluation of a Balanced 300-mb Height Analysis as a Reference Level for Satellte-Derived soundings. Albert Thomase11, Jr., December $1975,25 \mathrm{pp}$. (PB-253-058)

NESS 74 On the Estimation of Areal Windspeed Distribution in Tropical Cyclones With the Use of Satel1ite Data. Andrew Timchalk, August 1976, 41 PP. (PB-261-971)

NESS 75 Guide for Designing RF Ground Receiving Stations for TIROS-N. John R. Schnelder, December 1976, 126 Pp. (PB-262-931)

NESS 76 Determination of the Earth-Atmosphere Radiation Budget from NOAA Satellite Data. Arnold Gruber, November $1977,31 \mathrm{pP}$. (PB-279-633)

NESS 77 Wind Analysis by Conditional Relaxation. Albert Thomase11, Jx., January 1979. 


\title{
NOAA SCIENTIFIC AND TECHNICAL PUBLICATIONS
}

The Vational Oceanic and Atmospheric Adminustration was established as part of the Department of Commerce on October 3, 1970. The mission responsibilities of NOAA are to assess the socioeconomic impact of natural and technological changes in the environment and to monitor and predict the state of the solid Earth, the oceans and their living rcsources, the atmosphere, and the space environment of the Earth.

The major components of NOAA regularly produce various types of scientific and technical information in the following kinds of publications:

PROFESSIONAL P.APERS - Important definitive research results, major techniques, and special investigations.

CONTRACT AND GRANT REPORTS - Reports prepared by contractors or grantees under NOAA sponsorship.

ATLAS - Presentation of analyzed data generally in the form of maps showing distribution of rainfall, chemical and physical conditions of oceans and atmosphere, diseribution of fishes and marine mammals, ionospheric conditions, etc.
TECHNICAL SERVICE PUBLICATIONS - Reports containing data, observations, instructions, etc. A partial listing includes data serials; prediction and outlook periodicals; technical manuals, training papers, planning reports. and information serials; and miscellaneous technical publications.

TECHNICAI REPORTS - Journal quality with extensive details, mathematical developments, or data listings.

TECHNICAL MEMORANDUMS - Reports of preliminary, partial, or negative research or technology results, interim instructions, and the like.

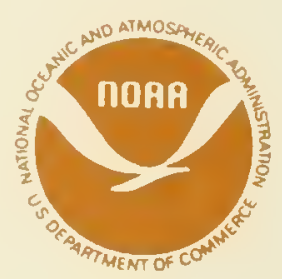

Information on availability of NOAA publications can be obtained from:

\author{
ENVIRONMENTAL SCIENCE INFORMATION CENTER (D822) \\ ENVIRONMENTAL DATA AND INFORMATION SERVICE \\ NATIONAL OCEANIC AND ATMOSPHERIC ADMINISTRATION \\ U.S. DEPARTMENT OF COMMERCE \\ 6009 Executive Boulevard \\ Rockville; MD 20852
}

